\title{
Anisotropy of additively manufactured AlSi10Mg: threads and surface integrity
}

\author{
Rizwan Ullah $^{1}$ • Jan Sher Akmal ${ }^{1} \cdot$ Sampsa V. A. Laakso ${ }^{1}$. Esko Niemi ${ }^{1}$ \\ Received: 5 September 2019 / Accepted: 24 March 2020 /Published online: 19 April 2020 \\ (C) The Author(s) 2020
}

\begin{abstract}
Implementing additive manufacturing in an industry, particularly for critical applications of lightweight aluminum (AlSi10Mg), requires part properties that are both accurate and precise to conform to the intent of a robust design. In this experimental study, the objective was to evaluate anisotropy in part properties (i.e., flatness, surface roughness, surface porosity, surface hardness, pre-hole shrinkage, drilling thrust force, and thread-stripping force) when the part orientation (i.e., print inclination and recoater angle) was independently changed. This study developed and investigated an innovative procedure for determining anisotropy in part properties. The part properties were evaluated by designing specific features on a tailor-made flat plate. The replicas of the aluminum plate were additively manufactured at varying orientations using two commercial EOS parameter sets for the laserbased powder bed fusion technique. Conventional measurement equipment was used to analyze all the part properties, except the thread-stripping force, which was measured using a custom-made setup. All the part properties indicated a considerable degree of anisotropy, excluding the drilling thrust force. The printing parameters dictate the significance of the anisotropy. The anisotropy in flatness and pre-hole shrinkage decreases with an increased substrate temperature and a decrease in energy input and thermal gradient. The presence of surface overlapping contours in the scan strategy and an increased energy input can reduce anisotropy in surface roughness and hardness. No significant anisotropy was detected when the recoater angle was changed. This study helps designers establish and substantiate design for additive manufacturing that is within the limits of appropriate anisotropy for a robust design.
\end{abstract}

Keywords 3D printing $\cdot$ Direct metal laser sintering $($ DMLS) $\cdot$ Print orientation $\cdot$ Recoater angle $\cdot$ Machining allowance $\cdot$ Threads

\section{Introduction}

Additive manufacturing (AM) enables the production of parts with unprecedented geometric freedom through a digital control system. It is widely used in the automotive $[1,2]$, aerospace $[1,3]$, and medical $[4,5]$ industries, mainly to produce

Rizwan Ullah

Rizwan.ullah@aalto.fi

Jan Sher Akmal

Jan.akmal@aalto.fi

Sampsa V. A. Laakso

Sampsa.laakso@aalto.fi

Esko Niemi

Esko.niemi@aalto.fi

1 Department of Mechanical Engineering, Aalto University, Espoo, Finland end-use parts [1, 6], functional prototypes [1], and tooling [1, 7]. In the AM process, material is typically joined layer by layer to make parts from three-dimensional (3D) model data, as opposed to subtractive and formative manufacturing methodologies [8]. One of the AM technologies used to produce metal parts is powder bed fusion (PBF), in which thermal energy is used to selectively fuse regions of a powder bed [8].

Because of the wide range of applications in the automotive and aerospace industry, aluminum alloys, particularly AlSi10Mg, are among the most widely-studied non-ferrous metallic alloys. At $11 \%$ of silicon (eutectic point), this alloy has a sharp melting and solidifying temperature which makes it suitable for many casting and metal-PBF (m-PBF) processes [9]. Its major alloying elements are $9-11 \%$ silicon, $0.2-0.45 \%$ magnesium, and $0.55 \%$ iron.

Though the aluminum part properties and geometrical accuracy obtained by subtractive and formative manufacturing are well-established, these have been understudied with AM technologies [10]. 
During the m-PBF process, metal powder is spread by a recoater, and parts are additively manufactured at an inclined position on the substrate [11] to avoid a possible collision with the recoater [12]. Among other process parameters, support structures are crucial for a successful build because they provide rigidity and heat dissipation $[12,13]$. The thickness and density of the support structures can play an important role in determining distortions in the part [14]. Typically, a combination of block and solid supports is used to ensure part stability on the substrate $[12,15]$.

Studies [16-26] have proven that changing the printing parameters (laser power, scanning speed, layer thickness, scanning strategy, inert gas flow, and substrate temperature) can have a significant impact on the material properties. By carefully controlling these parameters, most defects that may be present in the m-PBF process, e.g., pores [12], dross [27], warpness, and shrinkage [28], can be reduced. Dross typically forms at the down-skin surfaces as a result of the partially melted powder particles [27]. Moreover, the presence of pores can have a serious impact on the material strength. In certain cases, a fatigue crack can grow through the pore, resulting in a premature failure [29]. The selection of appropriate printing parameters can improve surface roughness and reduce the number of pores in the AlSi10Mg [26, 27].

To this end, the original equipment manufacturers (OEM) of AM machines have standardized their AM parameters to confirm process assurance and repeatability for their machines. For example, the EOS [30] has standardized parameter sets according to the material, surface quality, mechanics, accuracy, speed, and cost. The laser power, scanning speed, layer thickness, hatch distance, stripe width, stripe overlap, and overlaps with contours (surfaces) [31] are predefined in the parameter sets.

The standardized m-PBF parameters allow the production of AlSi10Mg parts close to the design intent. However, this is inevitably followed by subtractive manufacturing (machining) to remove support structures and to obtain accurate part properties such as surface roughness, flatness, and threads for assembly interfaces in critical components.

Further, shrinkages occur as a result of the contraction in AlSi10Mg after it has been processed at high temperatures. Appropriate casting and machining allowances are generally added to achieve strict dimensions in the end-use part. For example, in the case of aluminum castings, a machining allowance of $2 \mathrm{~mm}$ is prescribed for a dimension which is less than $200 \mathrm{~mm}$ [32, page 68]. The ISO 6082-3 [33] standard prescribes tolerance and machining allowances for cast components. However, the requirement of machining allowance is little understood for the m-PBF of AlSi10Mg.

Though the standardized m-PBF parameters provide quality assurance to a certain extent, the orientation of the part in terms of the printing inclination and recoater angle may have a considerable impact on the material properties and part features. For example, the formation of dross varies with changes in the printing orientation [12]. Furthermore, the printing orientation-induced staircase effect can affect the flatness of a newly built surface $[34,35]$.

Because of the layer-wise building and rapid heating and cooling, material defects [36] and non-uniform mechanical properties can develop in the material [37]. Anisotropy exists when the material exhibits different values of a property in different directions [38, page 302-303]. Since the material is built vertically upwards, the material properties, e.g., tensile strength, yield strength, and elongation, become weaker in one direction compared with others $[30,31,39,40]$ owing to the resulting microstructural morphology. Typically, tensile specimens are pulled until failure under controlled conditions to determine the anisotropy associated with AlSi10Mg. However, the impact of defects, such as shrinkage, support rupturing [41], warpness [14], dross [20, 21, 42], and surface porosity, on the features of the part can fluctuate with varying printing orientations. The influence of surface defects arising from the m-PBF may be mitigated using subtractive manufacturing methods.

Therefore, there is indication and reason to believe that the impact of part orientation in terms of the printing inclination and recoater angle on the AlSi10Mg part properties is understudied, particularly in a unified setup involving multiple properties.

The aim of this study is to investigate the anisotropy in part properties, i.e., flatness, surface roughness, surface hardness, pre-hole shrinkage, surface porosity, drilling thrust force, and thread-stripping force, when the part orientation, i.e., the print inclination and recoater angle, is independently changed.

\section{Experimental method}

This study designed and investigated an innovative procedure for evaluating the anisotropy in parts made of an aluminum alloy (AlSi10Mg).

\subsection{Test plates}

Figure 1 shows the detailed geometry of the flat test plates modeled using Creo Parametric (4.0, PTC, Needham, MA, USA). The plates contain pre-holes with small deviations (machining allowances) of a nominal diameter, i.e., $4.2 \mathrm{~mm}$ and $6.8 \mathrm{~mm}$, required for drilling and tapping M5 and M8 internal threads. The minimum increment $(0.1 \mathrm{~mm})$ of the machining allowance was equal to the minimum feature size of an AM machine in the XY-plane, which was approximately the diameter of the focused beam. The pre-hole diameter and the subsequent machining allowances are presented in Table 1. The left-hand region of the plate (Fig. 1) was allocated for direct drilling into the solid material. The inter-hole distances were 
Fig. 1 The CAD geometry of a flat plate with a thickness of $8 \mathrm{~mm}$

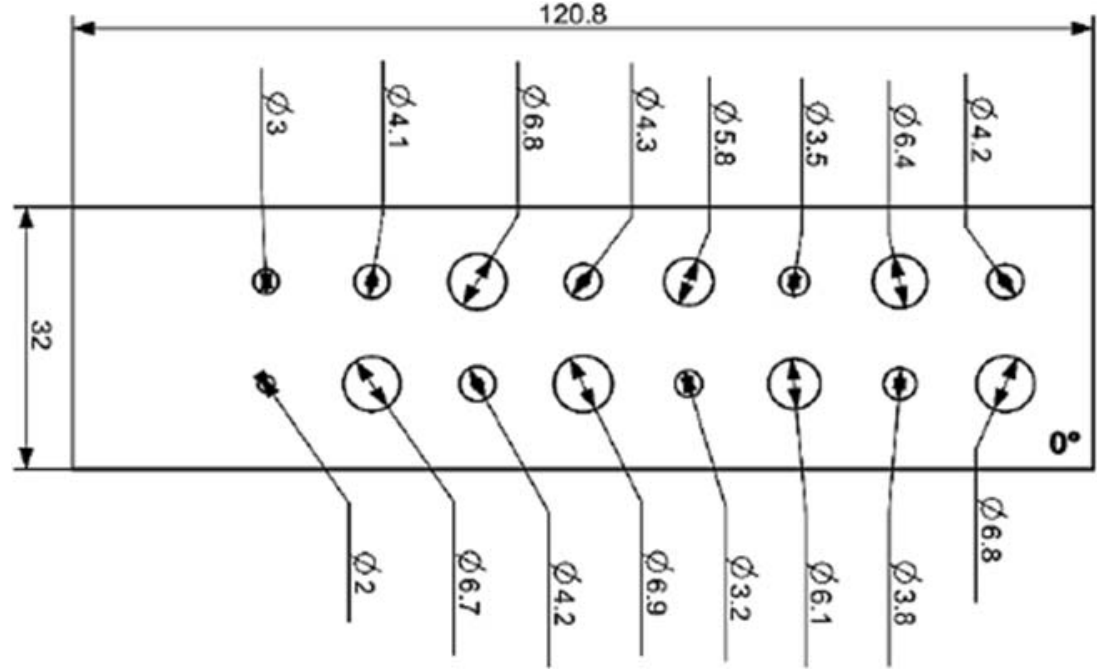

A combination of block and solid support structures was used to incline the plates. Identical support structures were used for all print jobs. The plates were removed from the substrate (also known as the build-platform) using a bandsaw, and the supports were milled away to form a flat bottom. The additively manufactured plates are shown in Fig. 6.

\subsection{Flatness error}

The flatness error was measured on the top surface of the plates (Fig. 6) using the Ruby CMM model 444 (CE Johansson AB, Eskilstuna, Sweden). The flatness error is calculated using the least mean square method. The measurements contained 60 points and were repeated three times for each surface to ensure reliability. The flatness error was measured with and without the substrate attached to the plates. The accuracy of the CMM was $20 \mu \mathrm{m}$.

\subsection{Surface roughness}

The surface roughness $\left(R_{\mathrm{a}}\right)$ was measured on the top surface with the Form Talysurf i120 (Taylor Hobson, Leicester,
Table 1 Pre-hole diameter and machining allowances of additively manufactured plates

\begin{tabular}{llll}
\hline $\begin{array}{l}\text { Pre-hole diameter } \\
(\mathrm{mm})\end{array}$ & $\begin{array}{l}\text { Machining allowance for 4.2- } \\
\text { mm drill }\end{array}$ & $\begin{array}{l}\text { Pre-hole diameter } \\
(\mathrm{mm})\end{array}$ & $\begin{array}{l}\text { Machining allowance for 6.8- } \\
\text { mm drill }\end{array}$ \\
\hline 4.3 & +0.1 & 6.9 & +0.1 \\
4.2 & 0.0 & 6.8 & 0.0 \\
4.1 & -0.1 & 6.7 & -0.1 \\
3.8 & -0.4 & 6.4 & -0.4 \\
3.5 & -0.7 & 6.1 & -0.7 \\
3.2 & -1.0 & 5.8 & -1.0 \\
2.0 & -2.2 & 3.0 & -3.8 \\
Direct drilling & $-4.2 \mathrm{~mm}$ & Direct drilling & $-6.8 \mathrm{~mm}$ \\
\hline
\end{tabular}


Fig. 2 Schematic of plate orientation with build platform

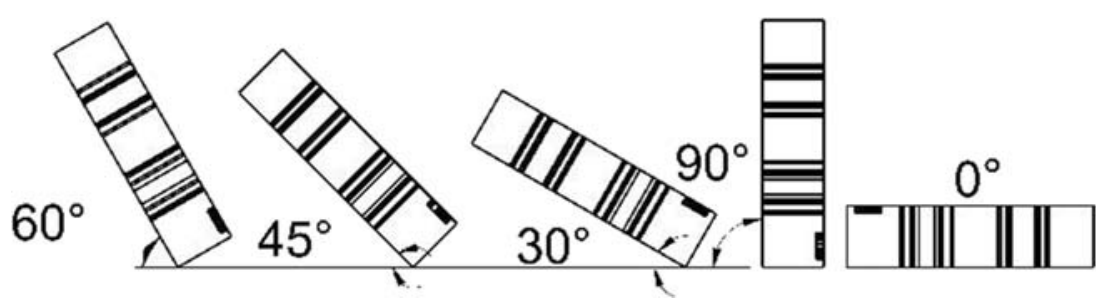

United Kingdom) with a back-and-forth stylus-type measuring tool according to the EN ISO 4288 standard. The cut-off length was $2.5 \mathrm{~mm}$.

\subsection{Surface hardness}

The hardness of the additively manufactured plates was measured on the top surface using the Brickers-220 (Gnehm, Thalwil, Switzerland) equipment and the Vickers V10 scale. A sample $(32 \mathrm{~mm} \times 12.5 \mathrm{~mm} \times 8 \mathrm{~mm})$ was sectioned from the additively manufactured plate. It was ground using $\mathrm{SiC}$ paper with the FEPA grit size P 1200. The hardness value was determined by measuring the length of the diagonal on a V10 scale (98.07 $\mathrm{N}$ force) according to the SFS-EN-ISO-6507-4 standard. The hardness was measured at three locations (upper, middle, and lower) on the top surface of the plates (Fig. 6) with regard to the substrate.

\subsection{Hole diameter}

The pre-holes in the additively manufactured plates (Fig. 6) were measured using a hole gauge set and a micrometer.

\subsection{Surface porosity}

The surface porosity was evaluated through microstructural analyses of the 4.2-mm and 6.8-mm pre-holes for each plate. Samples were prepared to observe the top surface of the preholes along the plane perpendicular to the hole axis. The samples were sectioned from the additively manufactured plates and were ground with $\mathrm{SiC}$ paper with a grit size of 800,1200 , and 2000. Subsequently, the samples were polished with $3-\mu \mathrm{m}$ and $1-\mu \mathrm{m}$ diamond paste. Keller's reagent was used as an etchant. The composition of the etchant is shown in Table 4. The duration of the etching was 25-30 s. Finally, the samples were washed with methanol and dried using a hand-held electric air dryer. The top surface was observed under an optical microscope $(\times 2.5$ magnification $)$. The resultant macrographs were analyzed using the ImageJ $(1.52 \mathrm{p}$, $\mathrm{NIH}$, Bethesda, MD, USA) software for measuring the surface area of pores.

\subsection{Drilling thrust force measurement}

A Kistler 9271 A [44] piezoelectric sensor was used to measure the axial thrust force during the drilling process.

An MX-520 (Matsuura, Fukui-city, Japan) 5-axis vertical machining center was used for drilling and tapping. Walter carbide drilling tools [45] were used to drill all the pre-holes with 4.2-mm and 6.8-mm drills. The drilled holes were taped using the Walter [45] M5 and M8 tapping tools, mentioned in Table 5. The drilling and tapping parameters were selected according to the original equipment manufacturer's (OEM) recommendations, as shown in Table 5.

The drilling was performed using a $5 \%$ solution of SwissCool 7722 with water as a coolant and lubricant. Similarly, the Rocol RTD compound was used for tapping.

Fig. 3 Representation of recoater angle

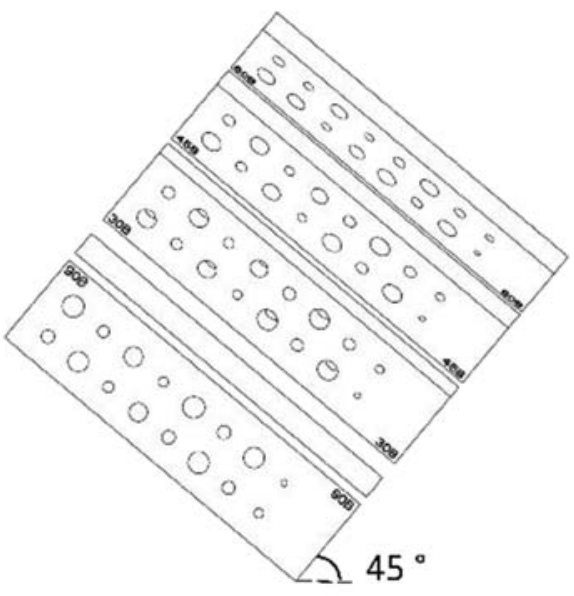


Table 2 AM parameters common to all sets

Global additive manufacturing parameters

\begin{tabular}{|c|c|c|c|c|c|c|c|c|}
\hline $\begin{array}{l}\text { ISO/ASTM } \\
\text { AM method }\end{array}$ & Machine & Software & Material & $\begin{array}{l}\text { Particle } \\
\text { size }\end{array}$ & $\begin{array}{l}\text { Chamber } \\
\text { atmosphere }\end{array}$ & $\begin{array}{l}\text { Plate layer } \\
\text { thickness }\end{array}$ & Support structure parameters & Post-processing \\
\hline $\begin{array}{l}\text { Powder bed } \\
\text { fusion }\end{array}$ & $\begin{array}{l}\text { EOS } \\
\text { M290 }\end{array}$ & EOSPRINT & AlSi10Mg & $20-80 \mu \mathrm{m}$ & Argon & $30 \mu \mathrm{m}$ & $\begin{array}{l}\text { Software: EOSPRINT-1.5 } \\
\text { Type: block and solid } \\
\text { Layer thickness } 60 \mu \mathrm{m} \\
\text { Original EOS parameter set: } \\
\text { Default_ExternalSupport }\end{array}$ & $\begin{array}{l}\text { Machining for } \\
\text { support removal }\end{array}$ \\
\hline
\end{tabular}

\subsection{Thread-stripping force}

The effect of the printing inclination and pre-hole diameter on the thread strength was measured using the ISO standard 8992. To this end, a custom-made tensile testing machine with the setup shown in Fig. 4 was employed to apply a tensile load. The additively manufactured plate was clamped in a manner which resisted the reciprocal motion of the mandrel. Four M8 bolts were used for clamping. The thickness of the plates was kept at $5 \mathrm{~mm}$ for stripping all the M5 and M8 threads, considering the peak load of the tensile machine and the strength of the bolt.

Because of the lack of an AM-specific standard for thread integrity, the guidelines of the ISO standard 899-2 were improvised. To this end, this study considered completely stripping the internal threads composed of aluminum to determine the thread-breaking strength.

The hardness requirements for the fixture and mandrel were fulfilled as defined by the standard. All the internal threads were stripped off using a new mandrel (a bolt in this case) per thread. The stripping force (tensile) was applied along the axis of the pre-holes.

\subsection{Benchmark}

In order to benchmark the integrity of additively manufactured threads, wrought (rolled) aluminum Al-6082 was drilled to obtain similar pre-holes. Further, these pre-holes were drilled and tapped to cut M5 and M8 threads. The subsequent drilling and stripping forces were measured in a similar manner to that of the additively manufactured aluminum. In addition to the pre-hole sizes, the location and arrangement of the holes were also identical.

\section{Results and discussion}

The additively manufactured plates of print job 1 resulted in ruptured supports (Fig. 5). Introducing denser supports through optimization would most probably have prevented the rupturing. No rupturing defects were observed in print jobs 2 and 3 (Fig. 6).

\subsection{Flatness error}

Figure 7 shows the flatness error of the plates induced by the parameters of print job 1 . This error was caused by the buildup of large thermal gradients from inadequate support structures. The large thermal gradients induced residual stresses and strained (warped) the plate to such an extent that the supports ruptured during the printing. The ruptured supports further aided the buildup of residual stresses.

The plate manufactured at a $90^{\circ}$ inclination yielded the least amount of flatness error. This is because a larger portion of the plate supported itself compared with the others. The solid material of the plate itself increases the heat transfer capability. Additionally, it contains the smallest amount of maximum energy input per layer compared with other orientations owing to the smallest amount of selectively melted cross-section area per layer. A lower energy input tends to

Table 3 AM job parameters summary

Additive manufacturing print job parameters

\begin{tabular}{|c|c|c|c|c|c|}
\hline Print job & Original EOS parameter set & Energy input & Substrate temperature & Recoater angle & Plate orientation angle \\
\hline 1 & AlSi10Mg_FlexM291.2.01 & $73.0 \mathrm{~J} / \mathrm{mm}^{3}$ & $35^{\circ} \mathrm{C}$ & $5^{\circ}$ & \multirow[t]{3}{*}{$0^{\circ}, 30^{\circ}, 45^{\circ}, 60^{\circ}$, and $90^{\circ}$} \\
\hline 2 & A1Si10Mg_200C_M291_1.11 & $49.9 \mathrm{~J} / \mathrm{mm}^{3}$ & $200{ }^{\circ} \mathrm{C}$ & $5^{\circ}$ & \\
\hline 3 & AlSi10Mg_200C_M291_1.11 & $49.9 \mathrm{~J} / \mathrm{mm}^{3}$ & $200{ }^{\circ} \mathrm{C}$ & $45^{\circ}$ & \\
\hline
\end{tabular}


Table 4 The composition of Keller's reagent used for AlSi10Mg

\begin{tabular}{llll}
\hline $\mathrm{H}_{2} \mathrm{O}$ & $\mathrm{HCl}$ & $\mathrm{HF}$ & $\mathrm{HNO}_{3}$ \\
\hline $95 \mathrm{ml}$ & $1.5 \mathrm{ml}$ & $1 \mathrm{ml}$ & $2.5 \mathrm{ml}$ \\
\hline
\end{tabular}

induce a lower degree of deformation, particularly when coupled with adequate heat transfer.

The plate manufactured at a $0^{\circ}$ inclination provides the second smallest amount of flatness error. This is because it contains the highest amount of cross-section area of the support structures which is in contact with the substrate. A greater cross-section area of supports in contact with the substrate enables a higher solidification rate owing to an increased capability of heat transfer. Further, it allows a greater degree of support that anchors the part to the substrate.

The flatness error decreases from a 30 to a $60^{\circ}$ build orientation because the maximum energy input per layer and the cross-section area of the supports decrease during this transition. A greater amount of maximum energy input per layer is prone to cause a greater amount of distortions, particularly when associated with a lower amount of heat sink and support. In this case, the lower amount of support cross-section means that the plate has a greater tendency to support itself with solid material which aids heat transfer. Further, the variation in energy input per layer caused by the varying cross-section area of the selectively melted geometry also decreases during this transition, which results in a lower flatness error.

The flatness error without the substrate follows a similar trend to that of the one observed with the substrate. However, the error has intensified. In this case, the residual stresses of the part, which had been sustained by the supports anchored to the substrate, have further deformed the plates when the substrate was separated through machining. The intensity of the increase in flatness error is proportional to the residual stresses induced by the maximum energy input per layer and the decreasing heat transfer capability. The machining of the plate supports converts residual stresses induced by the impinging laser energy to strain which results in plate distortions. Additionally, the heat generated by the machining process can also assist preinduced residual stresses to cause distortions in the plate geometry. This effect is mitigated at a $90^{\circ}$ inclination because the

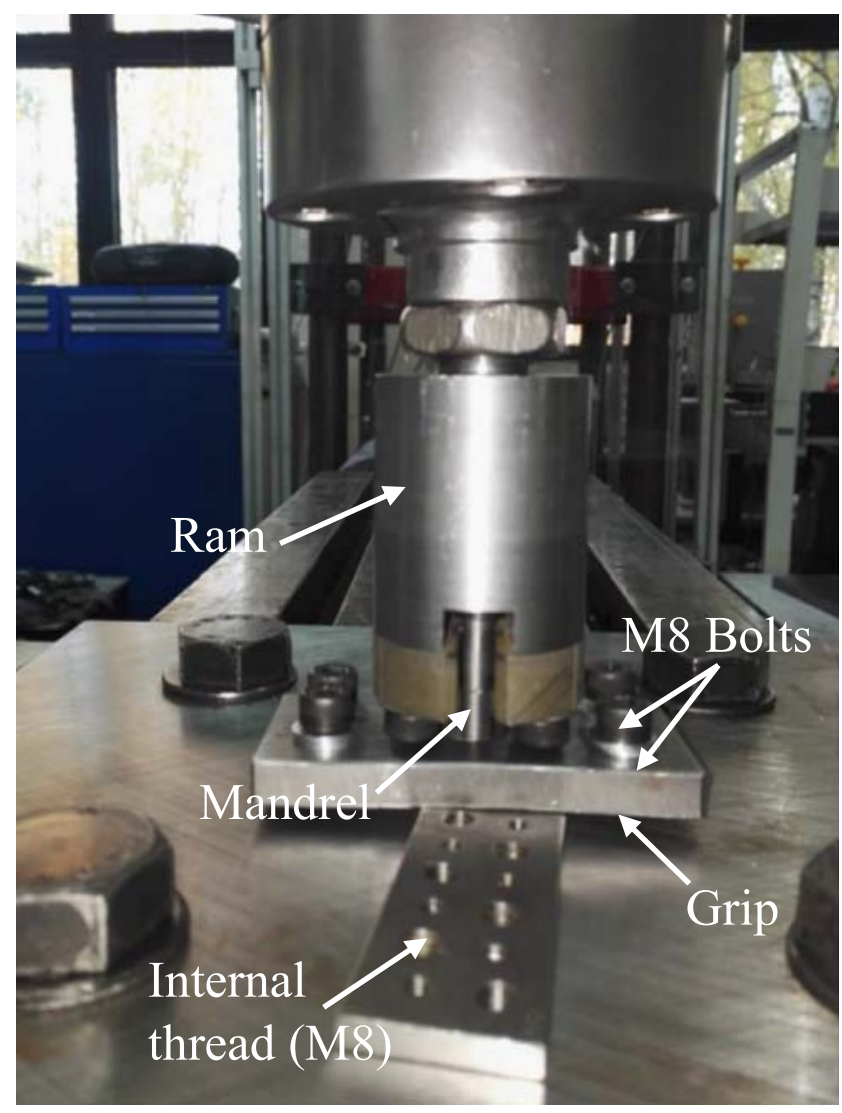

Fig. 4 Axial tensile test setup for internal thread-stripping forces

part was mainly supported by its own solid material and had the smallest amount of support cross-section area.

Though the $90^{\circ}$ inclination of the plate yielded the minimal flatness error, the duration and cost of the print job of this individual plate would be the maximum, comparatively. Similarly, the duration of the print job would increase from 0 to $60^{\circ}$, which would also increase the costs as well. Therefore, designers should consider the trade-offs between the flatness error, the duration of the print job, and the cost.

Figures 8 and 9 present the flatness error generated by print jobs 2 and 3. The error is reduced by approximately half compared with print job 1 because of an increase in the substrate temperature to $200{ }^{\circ} \mathrm{C}$ and the accompanying EOS original parameter set shown in Table 3.
Table 5 OEM recommended machining parameters

\begin{tabular}{llllll}
\hline Drills & Product name & $f^{*}$ & $V_{c}^{* *}$ & Point angle & No. of flutes \\
& A3299XPL-4.2 & 0.11 & 60 & $140^{\circ}$ & 2 \\
& A7191TFT-6.8 & 0.11 & 60 & $140^{\circ}$ & 2 \\
Taps & Product name & Tapp material & $V_{c}$ & Tapp coating & Pitch (mm) \\
& E2031466-M5 & HSS & 6.3 & TiN & 0.8 \\
& E2031466-M8 & HSS & 10 & TiN & 1.25 \\
\hline
\end{tabular}

$*$ Feed $=\mathrm{f}(\mathrm{mm} / \mathrm{rev})$

$* *$ Cutting speed $=\mathrm{V}_{\mathrm{c}}(\mathrm{mm} / \mathrm{min})$ 


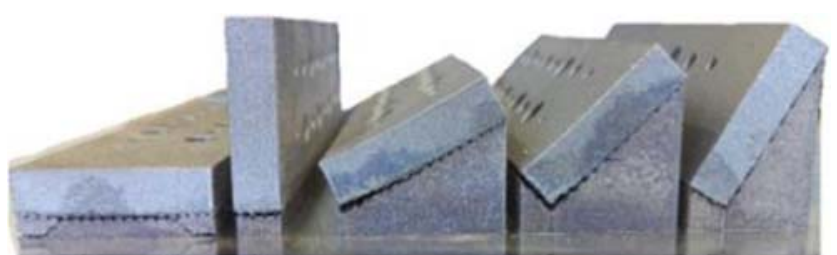

Fig. 5 Rupturing of supports in print job 1

The increase in the substrate temperature allows for a decrease in the impinging laser energy needed to selectively melt the regions of the powder bed. This enables a significant reduction in the buildup of large thermal gradients. As a result, the support structures were not ruptured, and accounted for a reliable heat transfer throughout the print job. The increased temperature also enables stress relief during the print job, which also explains the consistency and reduction in the flatness error.

No significant changes in the flatness error were observed between print jobs 2 and 3 when the recoater angle was changed. Since a lower surface area of initial contact with the recoater has a lower probability of striking the recoater, the recoater angle of $45^{\circ}$ may increase the chances of a successful print.

The variation in the flatness error, observed in Figs. 8 and 9 , is most probably caused by the uncertainty in the

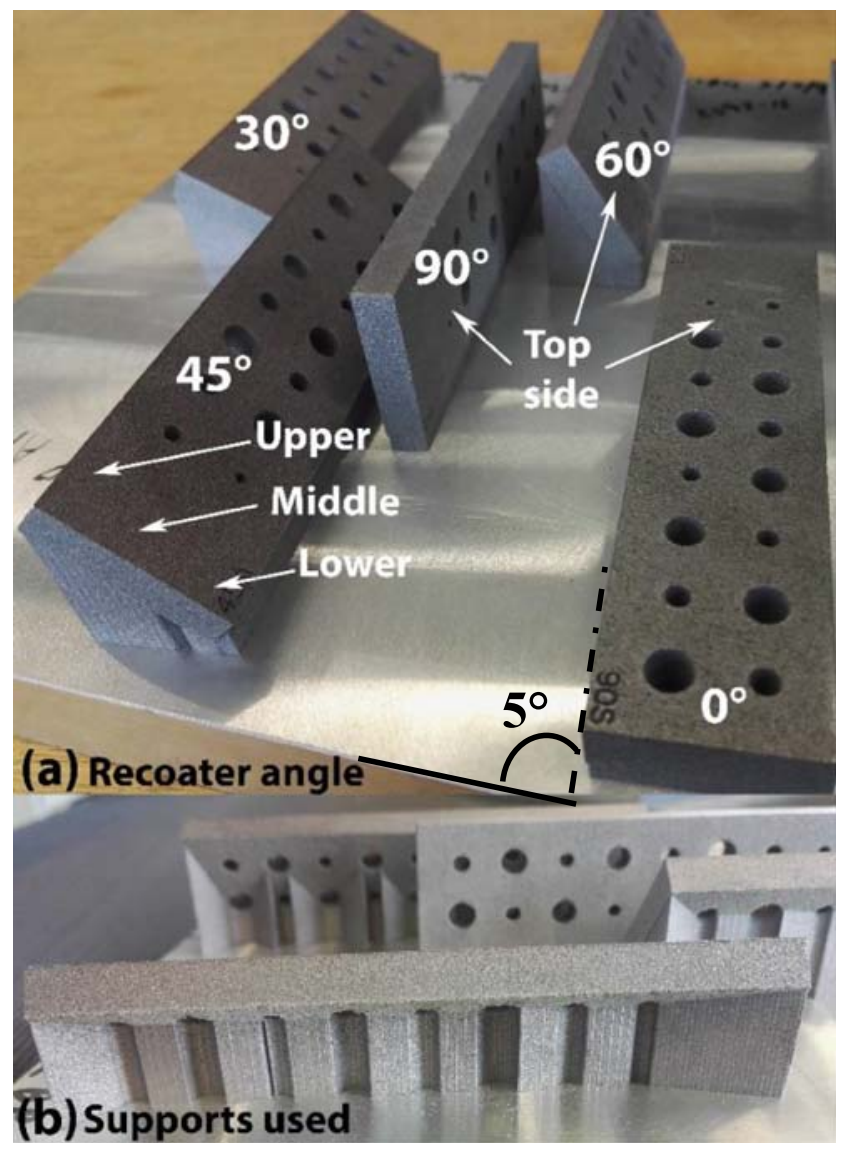

Fig. 6 The additively manufactured plates of print job 2 at five printing inclinations a recoater angle and $\mathbf{b}$ the structure of the supports

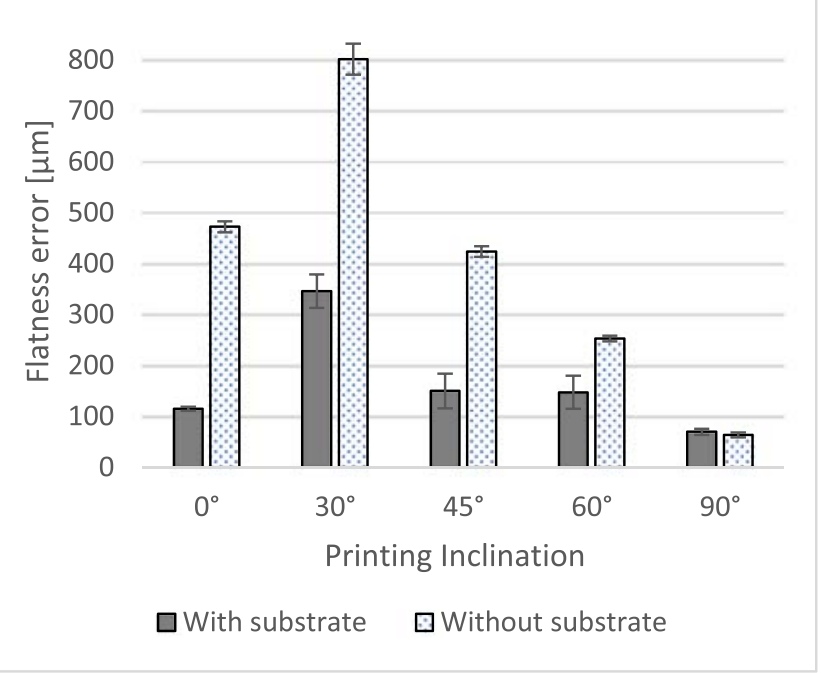

Fig. 7 Flatness error of print job 1

measurement equipment and process. The variation in the flatness error with and without the substrate is significantly decreased compared with print job 1 as a result of the significant reduction in the residual stresses. The slight decrease in the flatness error that is clearly visible in Fig. 9 may have been caused by the springback effect after the supports were removed from the plates. When considering the print duration and the subsequent cost, the plate manufactured at a $0^{\circ}$ inclination can yield favorable results.

For benchmarking purposes, the flatness error of the conventionally manufactured and machined aluminum 6082 plate was measured to be $35 \mu \mathrm{m}$.

\subsection{Surface roughness}

The dependence of the surface roughness on the printing inclination and recoater angle is illustrated in Fig. 10.

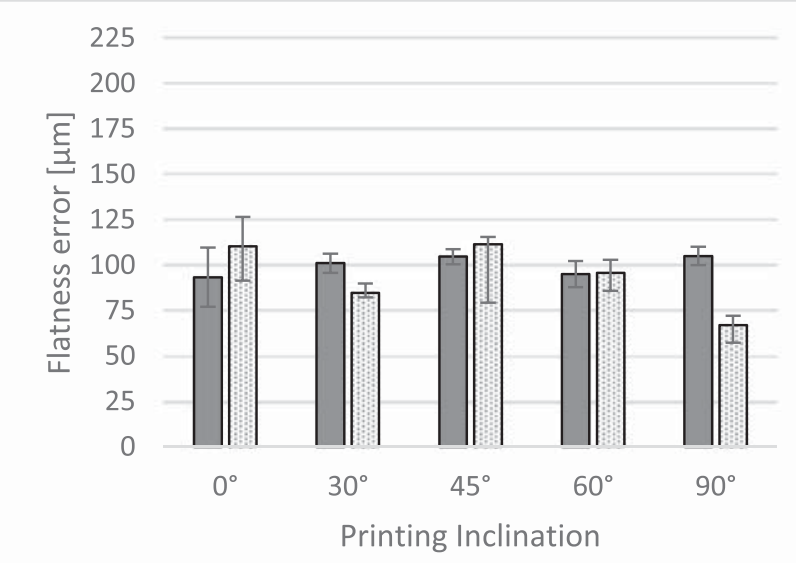

$\square$ With substrate $\square$ Without substrate

Fig. 8 Flatness error of print job 2 


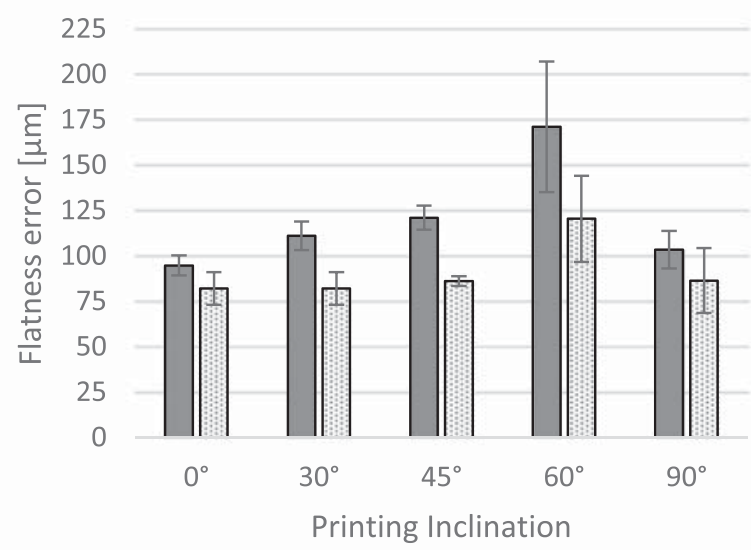

$\square$ With substrate $\square$ Without substrate

Fig. 9 Flatness error of print job 3

The surface roughness varies significantly according to the microstructural morphology inherited from the printing parameters (original EOS parameter set and substrate temperature) and printing inclination, as shown in Fig. 11. The minor fluctuation in surface roughness with varied recoater angles can be accounted for by the uncertainty of the measurements.

The printing parameters of print job 1 yielded significantly lower surface roughness than print jobs 2 and 3, except for a $0^{\circ}$ inclination. This is because the parameters of print job 1 are optimized for good surface quality that includes surface overlaps with contours.

In the case of print job 1, the surface roughness decreases from a 0 to a $90^{\circ}$ inclination. It is highest at a $0^{\circ}$ inclination because the surface roughness is measured over the repeated melt pool stripes and stripe overlaps where the melt pool has a width of approximately $100 \mu \mathrm{m}$. It is lowest at a $90^{\circ}$

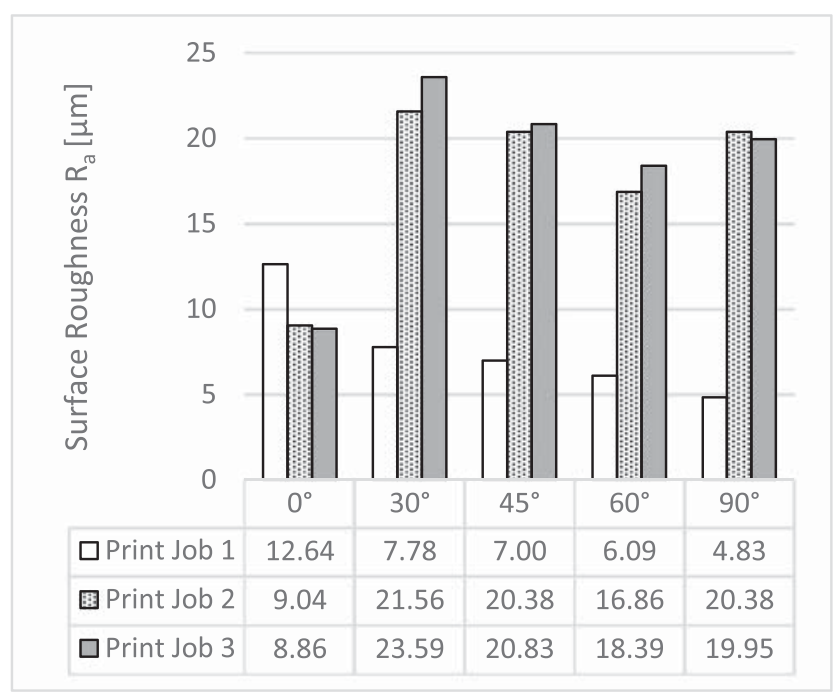

Fig. 10 Surface roughness of all print jobs inclination because it is measured over the overlapped contours with a layer thickness of $30 \mu \mathrm{m}$.

The decrease in roughness from 30 to $60^{\circ}$ is caused by the staircase effect shown in Fig. 12. During this transition, the staircase effect causes a decrease in the length of the perpendicular distance (Fig. 12) from the measurement surface of the plate to the inner edge of the staircases generated by the layerby-layer principle.

In the case of print jobs 2 and 3, the lack of surface overlaps with contours significantly increases the surface roughness. As a result, the plates inclined from 30 to $90^{\circ}$ provide a considerably greater surface roughness. The $0^{\circ}$ inclination is not affected by the absence of surface overlaps with contours because the measured surface does not contain any surface overlaps.

Further, the higher substrate temperature of $200{ }^{\circ} \mathrm{C}$ can aid in the conglomeration of semi-fused powder particles to the skin of the plates which is in contact with the powder. The intensity of this effect can be described by the angle of inclination or the staircase effect. The surface roughness decreases to some extent from a 30 to a $60^{\circ}$ inclination because the surface area (perpendicular to the build direction) generated by the staircase effect decreases from a 30 to a $60^{\circ}$ inclination, which is illustrated by the base of the staircase ( 52 to $17 \mu \mathrm{m})$ in Fig. 12. Thus, the greater surface area that is in contact with the surrounding powder bed yields a greater surface roughness as a result of the greater intensity of the powder conglomeration.

The surface roughness is slightly increased at a $90^{\circ}$ inclination compared with $60^{\circ}$ because a flat overlapping surface can be more susceptible to heat accumulation than the staircase surface, leading to a slightly higher degree of powder conglomeration.

\subsection{Surface hardness}

The hardness also depends on the microstructural morphology inherited from the printing parameters and the printing inclination. Figures 13 and 14 present the hardness values obtained from print job 1 and print job 2 for the different printing inclinations and plate regions with respect to the substrate. The hardness obtained from the varied recoater angle in print job 3 was identical to print job 2.

Print job 1 provided significantly higher and more consistent hardness values than print jobs 2 and 3 . This is because the parameters of print job 1 were optimized to obtain distinct material properties including a higher energy input, regardless of fluctuation in the job duration and the amount of supports. A higher energy input can yield more rapid solidification and finer microstructural grains, leading to greater hardness.

In the case of print job 1 , the collective hardness of the plates decreases by a minor but noticeable amount from a 0 to a $90^{\circ}$ inclination. This is due to an increase in distance on 
Fig. 11 The transition of the melt pool stripe overlaps to layer overlaps with printing inclinations for print job 1

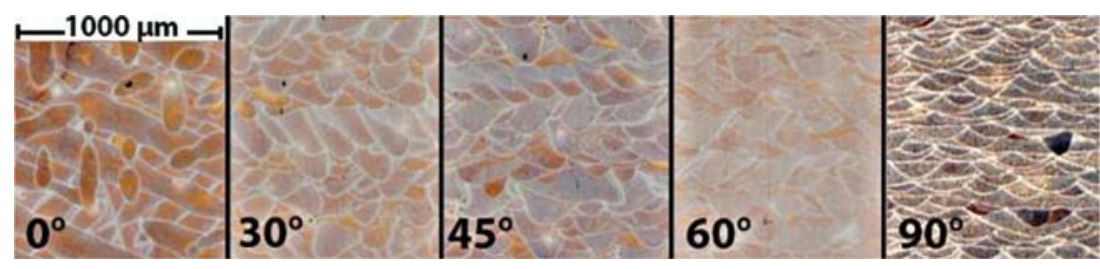

the $z$-axis between the measurement point regions from a 0 to a $90^{\circ}$ inclination.

For example, all three hardness measurement regions of the plate inclined at $0^{\circ}$ were measured on the very top surface, which had a constant height from the substrate, whereas the measurement regions of the plate inclined at $90^{\circ}$ contained the greatest distance on the $z$-axis between the measurement regions, which were at increasing heights from the substrate.

The layers that are melted below additional layers can undergo overaging as a result of the repeated heat cycles caused by the melting of additional layers on top. In this case, the overaging effect is not prevalent for each region, but their collective effect can be observed. The minor fluctuations in regional hardness for each inclination can be attributed to the uncertainty in measurement. Though the parameters of print job 1 are optimized to provide known properties, the resultant hardness values can vary by approximately $9 \%$.

The effect of overaging is further emphasized in the case of print jobs 2 and 3 because of the higher substrate temperature of $200{ }^{\circ} \mathrm{C}$ than the $35^{\circ} \mathrm{C}$ in print job 1 . The higher substrate temperature causes stress relief and reduces the solidification rate. The overaging effect is predominant in the measurement regions. It increases from the upper to the lower regions because the selectively melted layers above the regions increase. Since the upper measurement region contains the smallest number of melted layers above it, it undergoes peak aging, which leads to greater hardness. The greater hardness in the upper regions may be associated with a lack of silicon solubility compared with the lower regions [37].

The regional hardness variation at a $0^{\circ}$ inclination is minor and possibly occurred as a result of the measurement uncertainty. The decrease in the hardness of the measured regions from a 30 to a $90^{\circ}$ inclination is caused by an increase in the plate height. The increased height intensifies overaging in the measurement regions and reduces the hardness.
Though the hardness can increase along the $z$-axis of the build as a result of peak aging, the intensity of the increase depends on the substrate temperature.

The hardness can be within $9 \%$ from the maximum for the parameters of print job 1 at different heights above the substrate and printing inclinations. The hardness of the conventionally manufactured $\mathrm{Al} 6082$ was measured to be 124 on the HV 10 scale, which was quite close to the average hardness of 127 for print job 1 . However, designers should consider the anisotropic behavior of surface hardness for the parameters of print jobs 2 and 3 in their designs.

\subsection{Pre-hole shrinkage}

Shrinkage is detected in all the pre-holes evaluated in this study. Partial melting of powder particles, which range from 20 to $80 \mu \mathrm{m}$, to the surfaces can contribute to the shrinkage. Thermal contraction caused by large thermal gradients can also increase the risk of shrinkage. Furthermore, dross is formed in all the pre-holes that were inclined from 30 to $90^{\circ}$.

Figure 15 shows the method used for the calculation of the shrinkage and dross for each pre-hole. The shrinkage is calculated by subtracting the measured diameter $\left(d_{1}\right)$ from the intended or nominal diameter. The dross is calculated through subtraction of the measured diameter $d_{2}$ from $d_{1}$.

The shrinkage of the nominal diameter of the $4.2-\mathrm{mm}$ and 6.8-mm pre-holes is shown in Figs. 16 and 17 for each print job.

The shrinkage increases from 0 to $90^{\circ}$ inclinations for print job 1 in the case of a pre-hole size of $4.2 \mathrm{~mm}$ (Fig. 16), whereas it is somewhat more consistent for print jobs 2 and 3 , which differ in the recoater angle. The increase in shrinkage can be correlated with the morphology of the microstructural grains resisting contraction as the measured diameter shifts dependency from the melt pool stripe overlaps to layer overlaps during the transition from 0 to $90^{\circ}$.

Fig. 12 Staircase effect
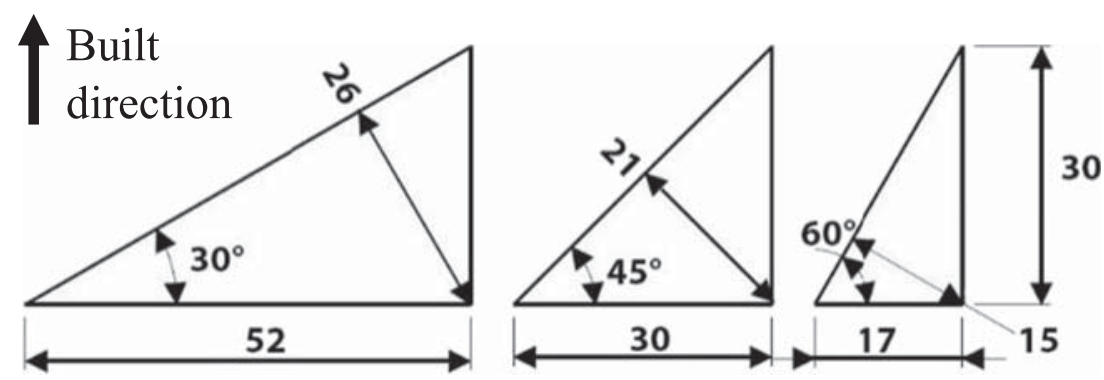


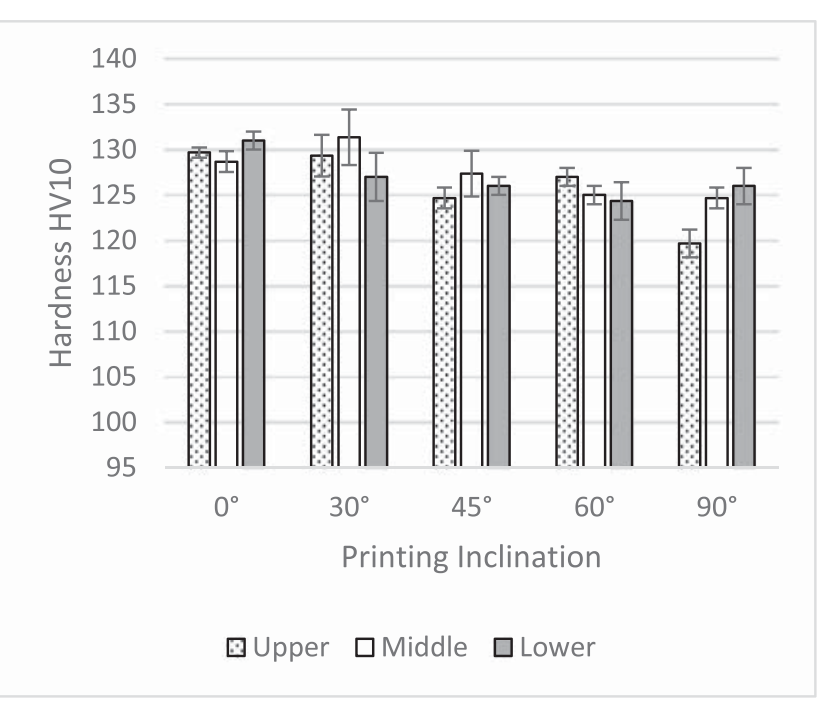

Fig. 13 Hardness with regard to printing inclinations in three measurement regions in print job 1

Further, the average shrinkage increases for the greater nominal diameter of $6.8 \mathrm{~mm}$ for each print job.

The formation of dross in the nominal diameter of the 4.2$\mathrm{mm}$ pre-hole is shown in Fig. 18 for each print job. An identical trend was observed for the nominal diameter of the 6.8$\mathrm{mm}$ pre-hole.

A significant amount of dross was formed within the preholes that were inclined from 30 to $90^{\circ}$ for each print job. In particular, it was formed in the down-skin surfaces as a result of a lack of sufficient support structures for heat conductivity and physical support. With inadequate solid material to conduct heat from the selectively melted down-skin, the powder that acts as an insulator as a result of poor heat conductivity is partially melted to form dross. Evidently, it can increase significantly as a function of the printing inclination, which maximizes at $90^{\circ}$. This is because the need to support the

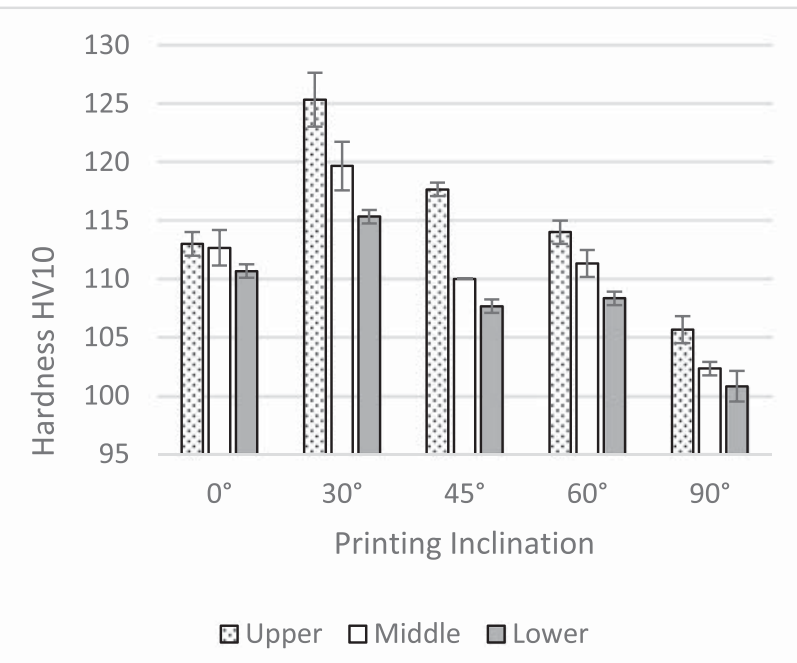

Fig. 14 Hardness with regard to printing inclinations in three measurement regions in print job 2 overhanging down-skin against gravity increases and the solid material to conduct heat away decreases from a 30 to a $90^{\circ}$ inclination.

Dross can be problematic if direct tapping of the pre-holes is intended. Further, it may cause sagging of the selectively melted down-skin and introduce porosity in the vicinity. It can be eliminated through the drilling of the pre-holes.

The measured diameter $\left(d_{1}\right)$ for the nominal $4.2-\mathrm{mm}$ and 6.8-mm pre-holes satisfies the medium (m) tolerance class of the ISO 2768-1 standard [46] for every print job. No significant changes in shrinkage and dross were observed when the recoater angle was changed.

\subsection{Surface porosity}

Figure 19 shows a top view of two sectioned pre-holes, 6.8$\mathrm{mm}$ with $45^{\circ}$ inclination for print jobs 1 (right) and 2 (left) at $\times 2.5$ magnification. The difference between both print jobs in the semi-circled overlapping of the melt pools is clearly visible. Print job 1 contains surface overlaps with contours that comprise surface pores with varying sizes and shapes. The pores are also present in the bulk of the material. The spherical pores are probably caused by the entrapment of argon in the melt pool during the melting process or may be due to the pores inside the feedstock powder [47, 48]. The nonspherical and irregularly shaped pores can result from a lack of adequate energy for complete melting or spatter ejection during the melting process $[47,48]$. Print jobs 2 and 3 were free of surface pores at this magnification.

Figure 20 shows the impact of surface porosity observed on the $4.2-\mathrm{mm}$ and $6.8-\mathrm{mm}$ sectioned pre-holes as a function of the printing inclination for print job 1 . The overall surface porosity may be negligible (Max. $0.71 \%$ ), depending on the application. Though the surface porosity of the $6.8-\mathrm{mm} \mathrm{sec}-$ tioned pre-hole is consistent to a certain degree (avg. 0.17\%) from a 0 to a $90^{\circ}$ inclination, it increases from 0.05 to $0.71 \%$ for the $4.2-\mathrm{mm}$ sectioned pre-hole, excluding a $60^{\circ}$ inclination. The decrease at a $60^{\circ}$ inclination is probably due to the excessive grinding of the sample surface, which partially removed the surface porosity. The $6.8-\mathrm{mm}$ sectioned pre-hole has a diameter approximately $62 \%$ larger than the $4.2-\mathrm{mm}$ one, which increases the observed surface area in the porosity analysis. Thus, the surface porosity of a $6.8-\mathrm{mm}$ sectioned pre-hole is observed over a larger area, which contributes to the surface porosity with a lower degree than a $4.2-\mathrm{mm} \mathrm{sec}-$ tioned pre-hole.

The increase in surface porosity for the $4.2-\mathrm{mm}$ sectioned pre-hole can be attributed to the dependency of the observed surface from the melt pool stripe overlaps to layer overlaps, coupled with a shift in the up-skin to down-skin exposure parameters for the inner surface of the pre-hole.

At a $0^{\circ}$ inclination, the observed surface depends strictly on the up-skin exposure parameters and the melt pool stripe 
Figure 15 A schematic of the pre-hole diameter measurement

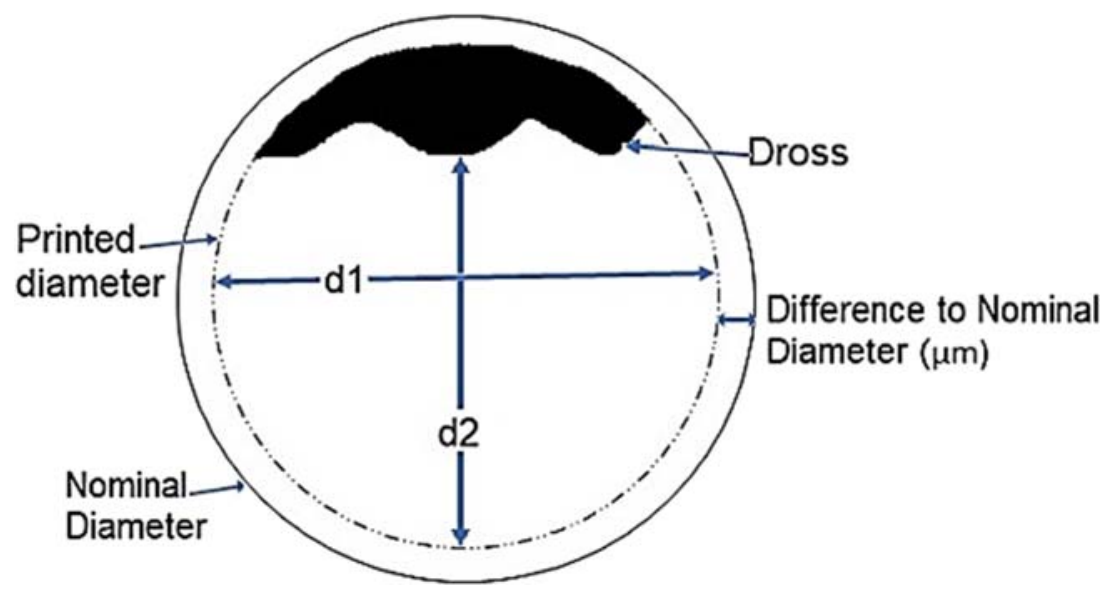

overlap, in particular the surface overlaps with contour, which are scanned at once. From 30 to $90^{\circ}$, the observed surface, in particular the surface overlaps with contour, consists of repeated melt pool layer overlaps (semicircled) coupled with a shift from up-skin to down-skin exposure parameters for selectively melting the inner surface of the pre-hole. The repeated initiation or ending points of scans can be susceptible to surface porosity as a result of partial melting or spatter ejection. Further, the formation of dross also increases from a 0 to a $90^{\circ}$ inclination, which can aid surface porosity.

\subsection{Thrust force measurement}

Figure 21 shows the drilling thrust force as a function of the pre-hole diameter for each printing inclination in print job 1 . Print jobs 2 and 3 provided similar results. No significant difference in the drilling thrust force was observed when the recoater angle was changed.

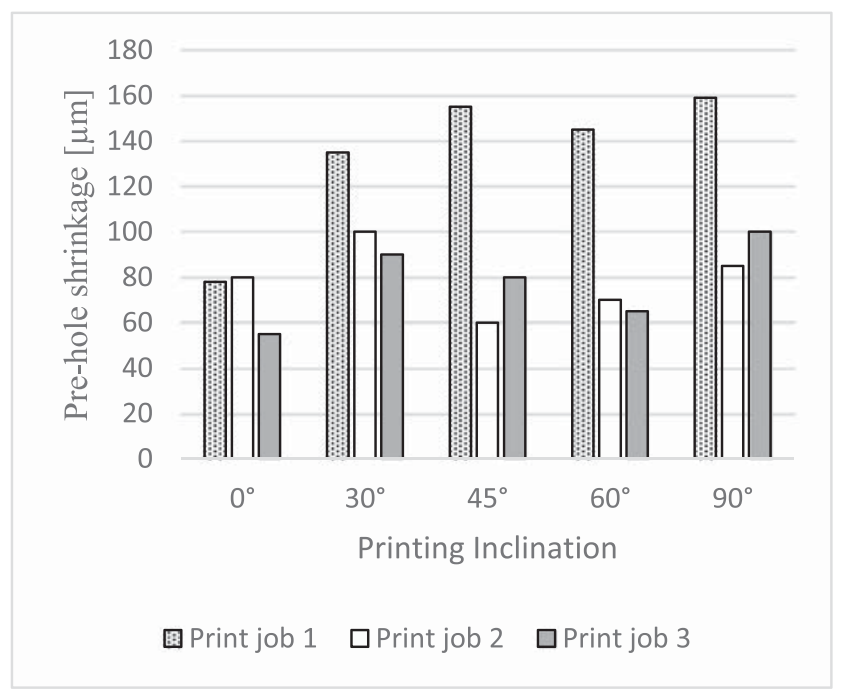

Fig. 16 Shrinkage of 4.2-mm pre-holes
The variation in the drilling thrust force from 0 to $90^{\circ}$ inclinations is minor and probably insignificant for most applications.

The force decreases with a logarithmic reduction for the $4.2-\mathrm{mm}$ and $6.8-\mathrm{mm}$ drills as the pre-hole diameter is increased. This is because the constant drill sizes, i.e., $4.2 \mathrm{~mm}$ and $6.8 \mathrm{~mm}$, remove a decreasing volume of material.

The $6.8-\mathrm{mm}$ drill requires a greater amount of force in contrast to the $4.2-\mathrm{mm}$ drill because it is subjected to the removal of a greater surface area and volume, comparatively.

The detectable level of the drilling thrust force can be reduced by $97 \%$ and $96 \%$ for $4.2-\mathrm{mm}$ and $6.8-\mathrm{mm}$ drills, respectively. A reduced drilling force can mitigate machininginduced stresses and can reduce tool wear. Though a larger pre-hole can reduce the drilling thrust force, it may create complications with regard to the spatial location of the actual pre-hole and the intended hole in case they are not aligned, resulting in a form error.

Figure 22 shows the average drilling thrust force for each print job with no pre-hole and the conventionally

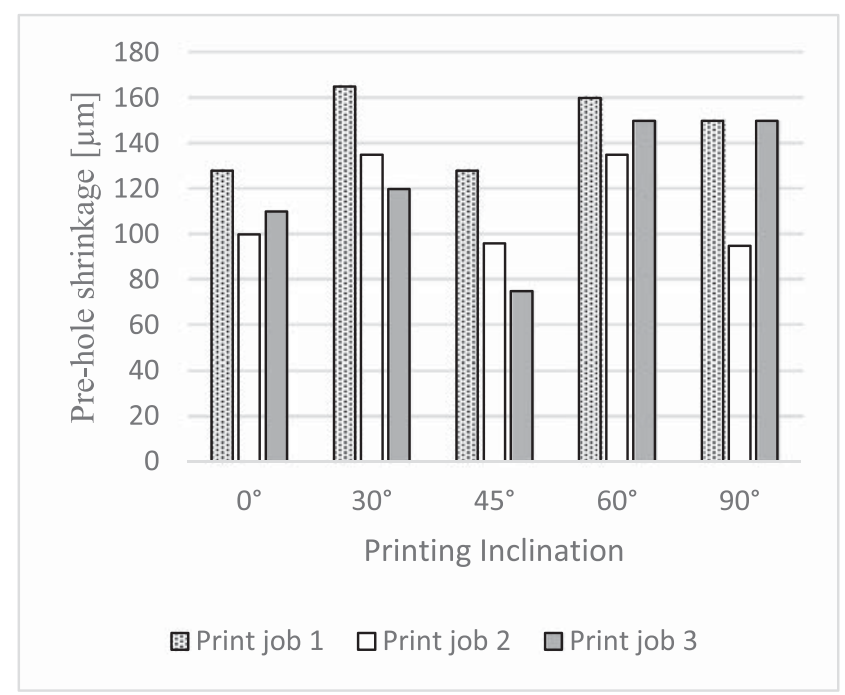

Fig. 17 Shrinkage of 6.8-mm pre-holes 


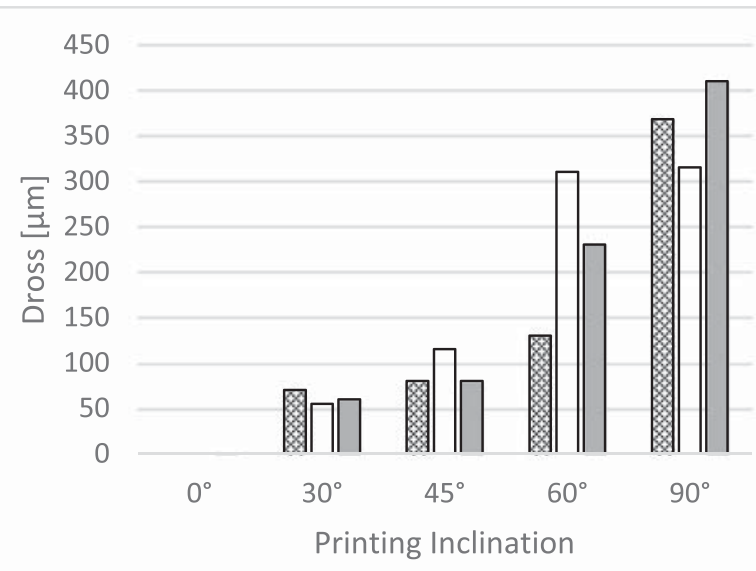

QPrint job $1 \quad \square$ Print job $2 \quad \square$ Print job 3

Fig. 18 Dross calculated for 4.2-mm pre-hole

manufactured Al-6082. Though the average drilling forces are consistent to a certain extent, print jobs 2 and 3 can yield drilling forces $17 \%$ and $12 \%$ higher than print job 1 . The increase in the drilling force can be associated with the reduced hardness of print jobs 2 and 3 evaluated in this study. Though a less hardened (more ductile) material generally promotes better machinability, resulting in greater surface roughness, accuracy, and hardness than a more hardened (less ductile) material, a less hardened material can produce greater cutting forces owing to plastic deformation and the formation

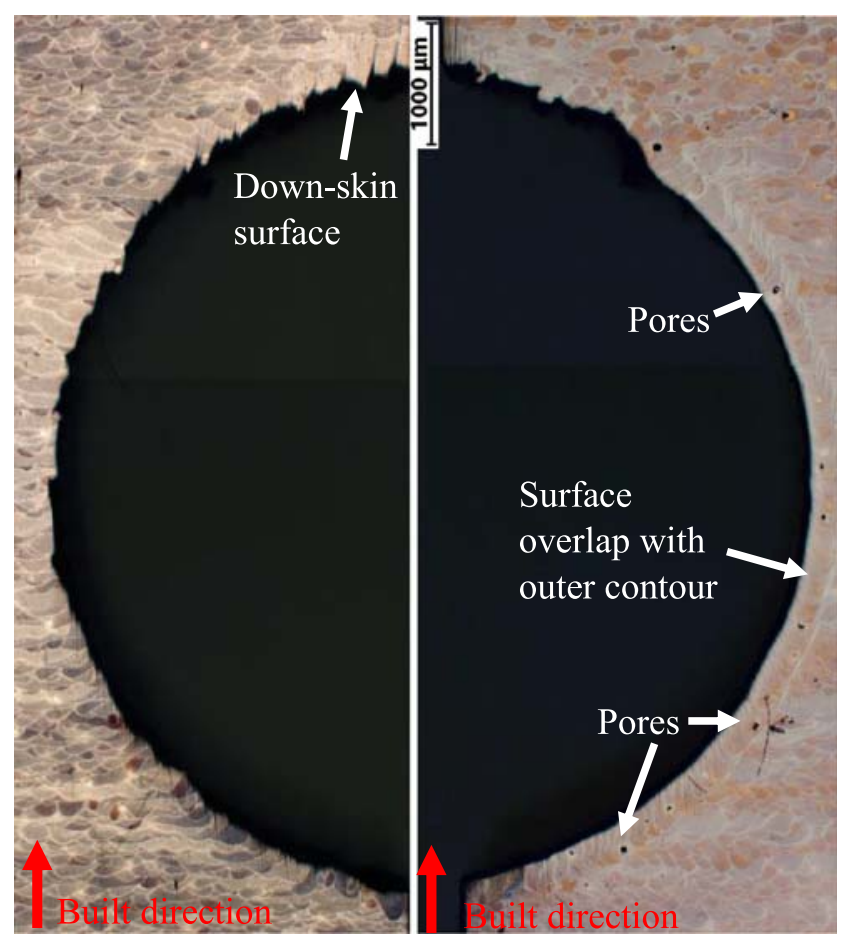

Fig. 19 A top view of the $6.8-\mathrm{mm}$ sectioned pre-hole inclined at $45^{\circ}$ in print job 2 (left) and print job 1 (right)

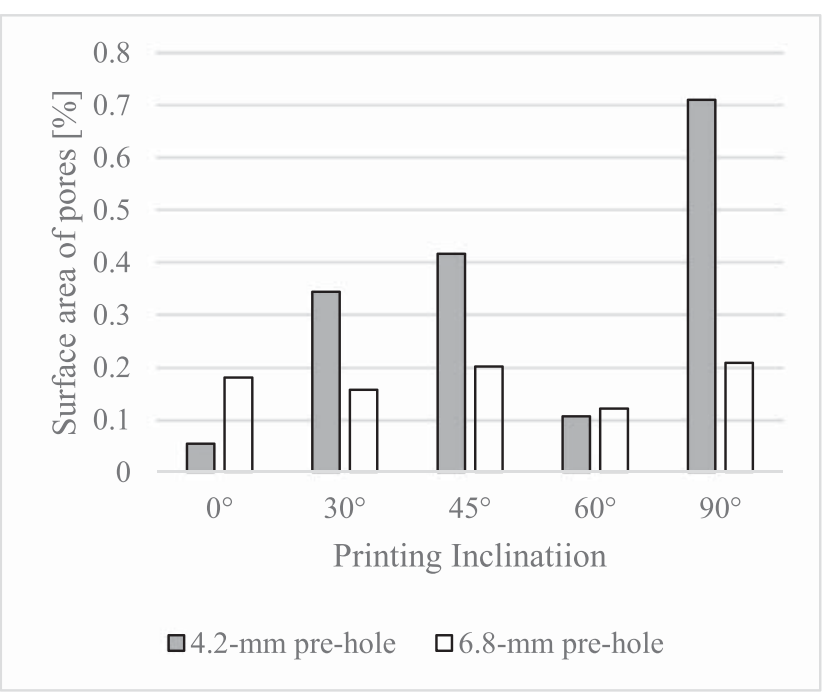

Fig. 20 Print job 1: surface porosity of the sectioned pre-holes

of continuous chips with built-up-edges [49, page 41], which may stick to the material and increase the cutting and thrust forces $[50,51]$, whereas a more hardened material (which is more brittle) may lead to lower cutting forces as a result of the lower fracture toughness and brittle removal of short intensified chips. Though the chip formation can be controlled through the cutting parameters, the cutting parameters for all the print jobs and Al-6082 were consistent in this study. The drilling force of the conventionally manufactured Al-6082 was similar (up to $8 \%$ ) to print job 1 .

Designers should consider additively manufacturing a small pre-hole for the intended hole to avoid large thrust forces. The pre-hole can significantly reduce the drilling thrust force compared with direct drilling, which may be critical for the structural integrity of delicate features such as thin walls.

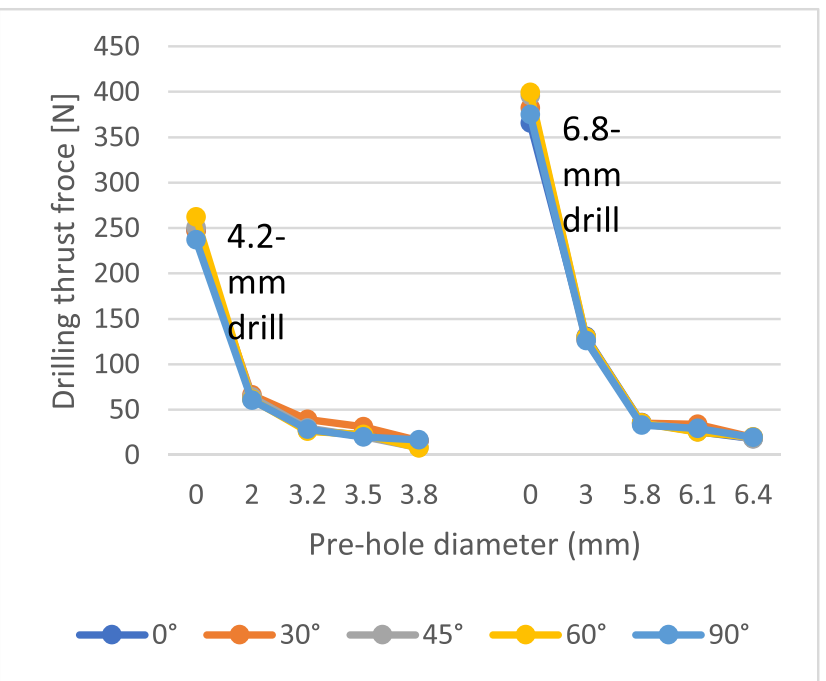

Fig. 21 Drilling thrust force with regard to printing inclination and prehole diameters of print job 1 


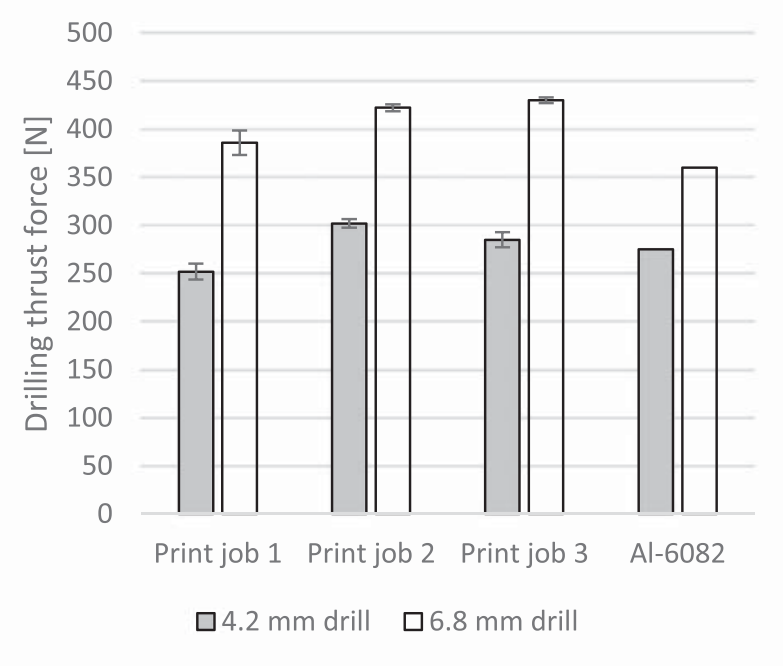

Fig. 22 Drilling thrust force $(\mathrm{N})$ without a pre-hole

\subsection{Thread-stripping forces}

Figure 25 shows the thread-stripping forces mapped into a color code with respect to the pre-hole diameter on the vertical axis and the printing inclination on the horizontal axis including both the M5 and M8 internal threads for each print job. Figure 24 shows the average thread-stripping force for every print job and the conventionally manufactured Al-6082.

Print job 1 contained a greater thread-stripping force of up to around $15 \%$ and $13 \%$ on average compared to print jobs 2 and 3 , respectively. The increase in the thread-stripping force is due to the greater hardness (13\%) obtained from print job 1 , comparatively.

The M8 thread required a greater force for stripping than the M5 thread because it provided a greater surface area and volume that was in direct contact with the bolt for resistance.

The thread-stripping force comprises a deviation from the maximum of 20\% for M5 and 29\% for M8 for print job 1. The stripping force increases from a 0 to a $90^{\circ}$ inclination until a certain pre-hole diameter for print job 1 , whereas it is somewhat consistent with a deviation of $16 \%$ and $15 \%$ from the maximum for print jobs 2 and 3, respectively.

For print job 1, the increase in the thread-stripping force is caused by the morphology of the microstructural grains as the force shifts dependency from the melt pool stripe overlaps to layer overlaps during the transition from 0 to $90^{\circ}$.

Figure 23 clarifies the built direction and the threadstripping force direction with regard to the morphology of the melt pool stripe overlaps and melt pool layer overlaps in a three-dimensional space.

The XY-plane contains overlaps of the laser scanning strategy which depicts the flat melt pool stripe overlaps that are rotated through $67^{\circ}$ between consecutive layers. At a $90^{\circ}$ inclination, the thread-stripping force tends to act on the melt pool stripes, particularly the ones that are parallel or close to parallel to its direction. Though the fracture may initiate at random defect locations in the melt pool stripes, it can propagate parallel to the tensile load direction and can completely or partially separate from the melt pool stripes [52].

The XZ- and YZ-planes contain layer overlapping which is shown by semicircle-shaped melt pools. At a $0^{\circ}$ inclination, the thread-stripping force tends to act on the melt pool layer boundaries which are perpendicular to its direction (Fig. 23). In this case, the failure can initiate at the melt pool layer boundaries and can propagate perpendicular to the applied tensile load direction, which can lead to an inter-layer failure caused by the detachment of the melt pools from their boundaries [31]. According to the surface porosity observed in this study, overlapping boundaries of the melt pool layer are more susceptible to the formation of defects such as spherical or irregular pores. Thus, the build-up of a greater stress concentration perpendicular to the applied load can accelerate failure.

The transition of the melt pool stripe overlaps to layer overlaps is shown in Fig. 11.

The anisotropy observed in print job 1 is predominant until a certain pre-hole diameter, for example a $3.8-\mathrm{mm}$ pre-hole for M5, after which the thread-stripping force decreases. The decrease in the force can be correlated to the presence of the surface overlapping contours and the surface porosity observed in its vicinity, which can accelerate failure. The width of the observed contours is approximately $200 \mu \mathrm{m}$, which results in a drill size of $4.2 \mathrm{~mm}$ when added to the pre-hole diameter $(3.8+2 \times 0.2=4.2 \mathrm{~mm})$. Thus, the pre-hole diameters larger than $3.8 \mathrm{~mm}$ contain partial or complete surface overlapping contours as a result of a lack of sufficient drilling. In Fig. 25, the pre-hole diameters larger than $3.8 \mathrm{~mm}$ mainly contain yellow-and green-coded regions depicting reduced thread-stripping forces for almost all inclinations.

This effect also occurs for M8, where certain inclinations experience premature failure coded by blue, green, and yellow regions that are inconsistent with the absence of the surface overlapping contour. However, it is not as dominant compared to M5 because the surface porosity observed for M8 was lower. The stripping force can decrease by around $7 \%$ and $4 \%$ for M5 and M8 as a result of premature failure.

The blue-coded region observed in M8 for a $30^{\circ}$ inclination without the surface overlapping contour was most probably caused by misalignment error in drilling and/or tapping leading to premature failure caused by a non-uniformly-used thread-stripping force.

The fairly consistent thread-stripping forces in print jobs 2 and 3 are inherited from the printing parameters, in particular, the absence of an overlapping contour and the increased substrate temperature of $200{ }^{\circ} \mathrm{C}$, which enable enhanced buildability and reduced internal stresses as a result of stress relieving. No significant change was observed in 
Fig. 23 Thread-stripping force shifting dependency from melt pool layer overlaps $\left(0^{\circ}\right)$ to stripe overlap $\left(90^{\circ}\right)$

\section{† Built direction}

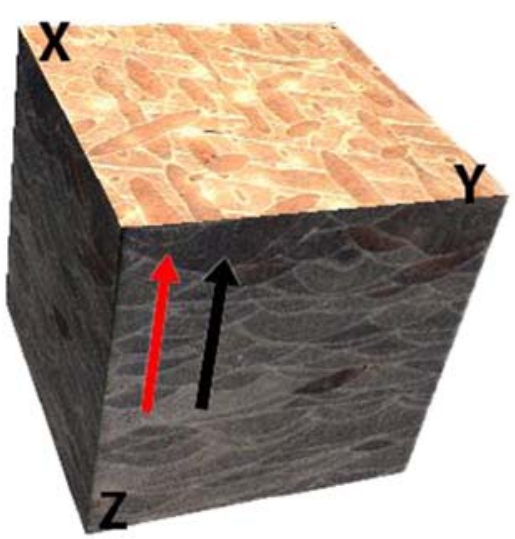

$0^{\circ}$ Inclination
† Stripping Direction

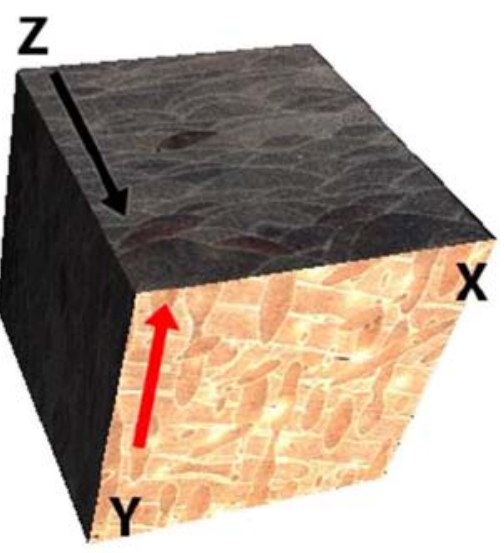

$90^{\circ}$ Inclination the thread-stripping forces when the recoater angle was altered.

The conventionally manufactured Al-6082 yielded lower thread-stripping forces for M5 and M8 threads compared with all print jobs. The strength of the additively manufactured AlSi10Mg thread can be $24 \%$ higher for M5 and $49 \%$ higher for M8 than the Al-6082 thread.

If a pre-hole is desirable to avoid large thrust forces that may be critical to the structural integrity of a component, designers should consider introducing a machining allowance of $0.3 \mathrm{~mm}$, to ensure the removal of surface overlapping contours containing surface and/or sub-surface porosity.

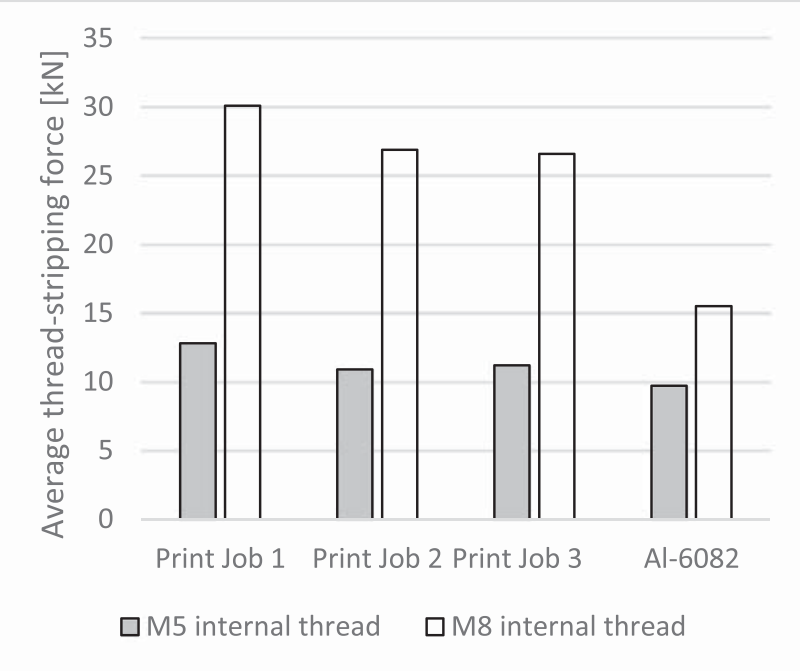

Fig. 24 Average thread-stripping force of all printing inclinations and pre-hole diameters of additively manufactured and wrought aluminum

\section{Conclusions}

This study designed and investigated an innovative procedure for evaluating the anisotropy in parts additively manufactured from AlSi10Mg aluminum alloy, particularly for flatness, surface roughness, surface hardness, surface porosity, pre-hole shrinkage, drilling thrust force, and thread-stripping force. The custom-designed test plates were additively manufactured using two commercial EOS parameter sets, i.e., AlSi10Mg FlexM291.2.01 and AlSi10Mg_200C_M291_1.11. The effect of the printing parameters was analyzed for the printing orientations at five inclinations and at two recoater angles and five printing inclinations. On the basis of the findings, we draw the following conclusions:

1. The AlSi10Mg_200C parameter set provided significantly lower and consistent flatness error at different inclinations as a result of the increased substrate temperature and decreased thermal gradients and energy input compared with the AlSi10Mg_Flex. In the case of AlSi10Mg_Flex, the printing inclinations in the order of decreasing flatness error are $30^{\circ}, 45^{\circ}, 60^{\circ}, 0^{\circ}$, and $90^{\circ}$ owing to the thermal gradients, and the availability of supports required to anchor the part to the substrate. No significant fluctuation in the flatness error was observed when the recoater angle was changed.

2. The AlSi10Mg Flex parameter set produced significantly lower surface roughness at different inclinations owing to the presence of surface overlapping contours compared with the AlSi10Mg_200C. In the case of AlSi10Mg Flex, it decreased by $62 \%$ from a 0 to a $90^{\circ}$ inclination because the morphology of the microstructure of the 


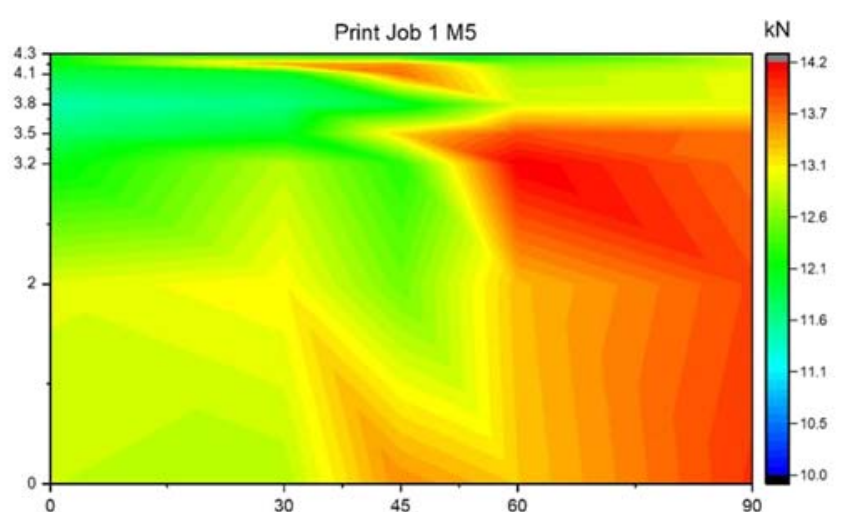

(a)

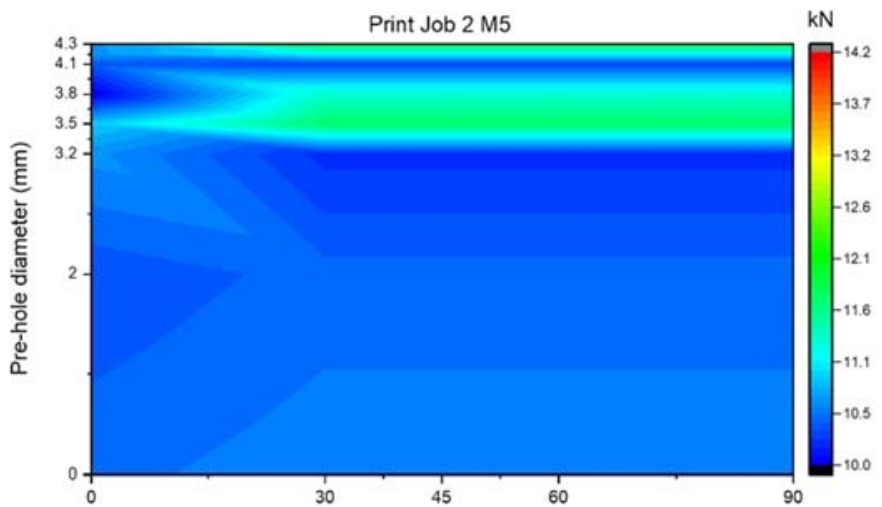

(c)

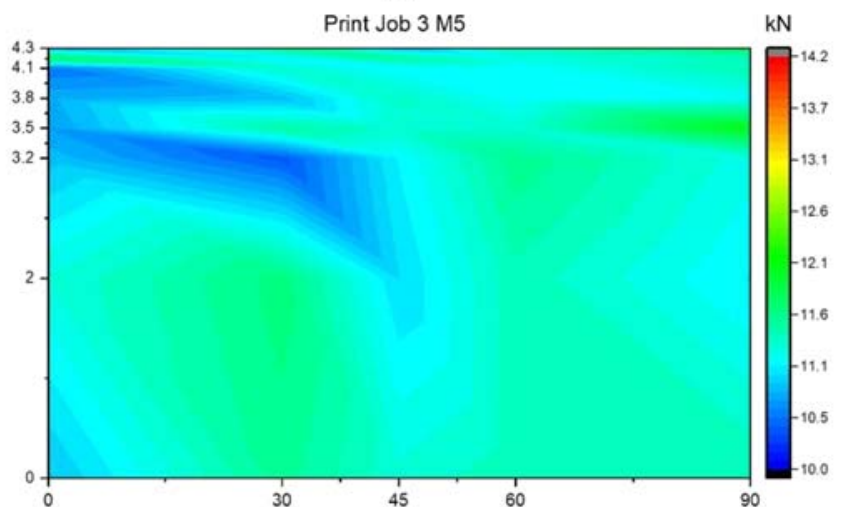

(e)

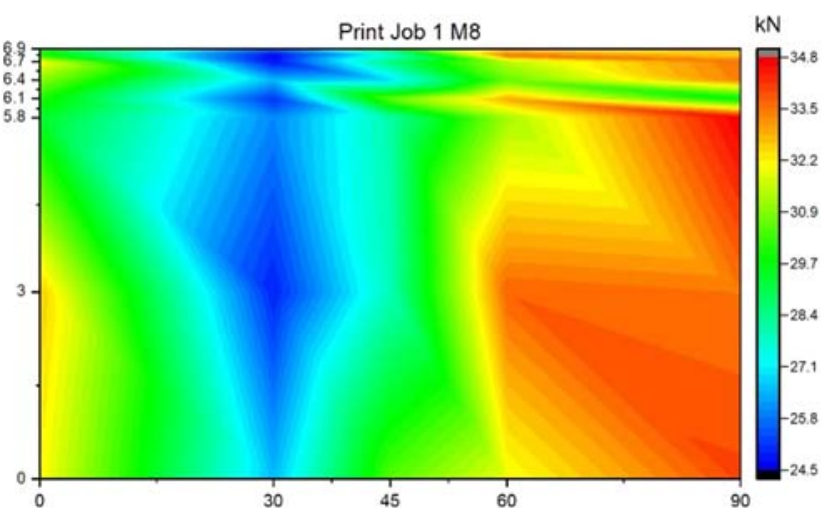

(b)

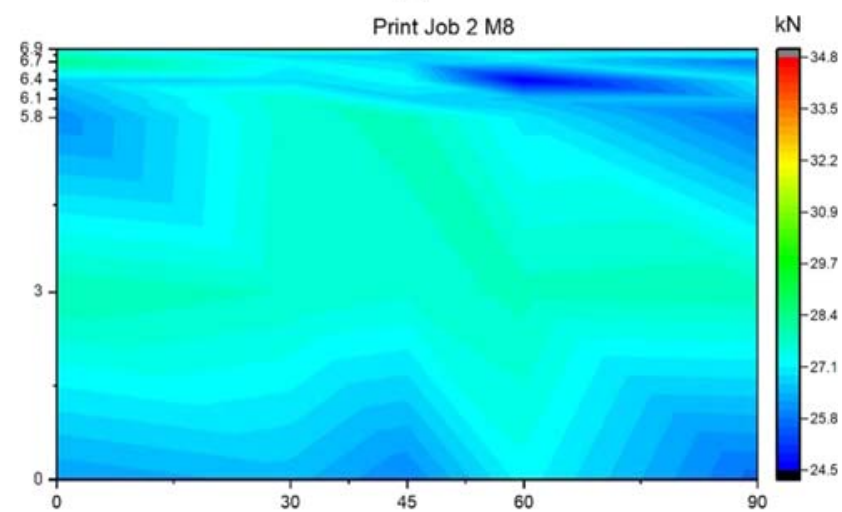

(d)

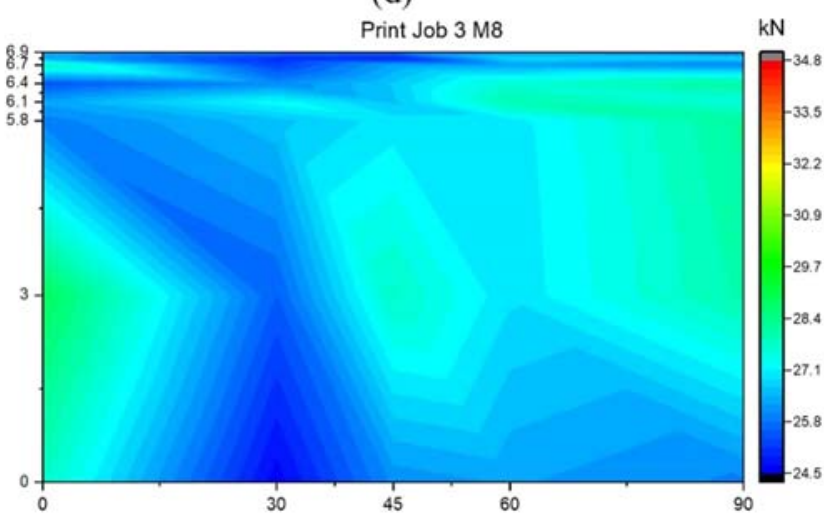

(f)

Fig. 25 Thread-stripping forces $(\mathrm{kN})$ of all print jobs with regard to printing inclinations and pre-hole diameter

measured surface changed from melt pool stripe overlaps to contour overlaps. In the case of the AlSi10Mg_200C, the trend changed owing to a lack of surface overlapping contour, the increased substrate temperature causing conglomeration of powder particles to the skin, and the staircase effect. No significant difference in the surface roughness was observed when the recoater angle was changed.

3. The AlSi10Mg_Flex parameter set yielded significantly greater and more consistent hardness at different inclinations owing to a higher energy input than the AlSi10Mg_200C. In the case of the AlSi10Mg_Flex, the decrease in the hardness from a 30 to a $90^{\circ}$ inclination is caused by an increase in plate height which intensifies overaging. The effect of overaging is further emphasized in the case of the AlSi10Mg_200C as a result of the increased substrate temperature causing stress relieving. No significant fluctuation in the hardness was observed when the recoater angle was changed.

4. The AlSi10Mg_Flex parameter set yielded significantly greater and more inconsistent pre-hole shrinkage at different inclinations as a result of a higher energy input and a lower substrate temperature producing a higher rate of solidification and a larger thermal gradient than the AlSi10Mg_200C. In the case of the AlSi10Mg_Flex, the 
shrinkage increased from a 0 to a $90^{\circ}$ inclination as a result of the staircase effect, resulting in the microstructural morphology resisting contractions as the measured diameter shifts dependency from the melt pool stripe overlaps to layer overlaps during the transition from 0 to $90^{\circ}$. Dross was formed in all the pre-holes for both parameter sets and increased from a 0 to a $90^{\circ}$ inclination. No significant difference in the pre-hole shrinkage and dross was observed when the recoater angle was changed.

5. In the AlSi10Mg_Flex parameter set, the presence of surface overlaps with contours contained surface pores with varying sizes and shapes. Though the surface porosity of the $6.8-\mathrm{mm}$ sectioned pre-hole was consistent to a certain degree (Avg. 0.17\%) from a 0 to a $90^{\circ}$ inclination, it generally increased from 0.05 to $0.71 \%$ for the $4.2-\mathrm{mm}$ sectioned pre-hole owing to the dependency of the observed surface on melt pool stripe overlaps to layer overlaps coupled with a shift in the up-skin to down-skin exposure parameters. No significant difference was observed in surface porosity when the recoater angle was changed with the AlSi10Mg_200C parameter set.

6. Both the AlSi10Mg_Flex and AlSi10Mg_200C parameter sets enabled an identical trend of drilling thrust forces that decreased with increasing pre-hole diameters. A minor variation in the drilling thrust force was observed from a 0 to a $90^{\circ}$ inclination that is probably insignificant for most applications. The AlSi10Mg_200C parameter set can yield an average drilling thrust force that is up to $17 \%$ higher than the AlSi10Mg_Flex owing to reduced hardness causing plastic deformation and the formation of continuous chips with built-up edges. No significant difference in the drilling thrust force was observed when the recoater angle was changed. The drilling thrust force of the conventionally manufactured Al-6082 was similar (within 8\%) to that of the AlSi10Mg_Flex parameter set.

7. The AlSi10Mg_Flex parameter set allowed for a threadstripping force up to around $15 \%$ higher because of its greater hardness (13\%) compared with the AlSi10Mg_200C. In the case of the AlSi10Mg_Flex parameter set, the thread-stripping force increased by up to $9.4 \%$ from a 0 to a $90^{\circ}$ inclination owing to the shift in dependency from the melt pool stripe overlaps to layer overlaps that trigger different failure mechanisms. The anisotropic increase in the thread-stripping force was predominant until the surface overlapping contour and the surface porosity located in its vicinity were not completely removed through drilling, resulting in a decreased thread-stripping force as a result of the premature failure. The premature failure reduced the thread-stripping force by approximately $7 \%$ for M5 and $4 \%$ for M8. During the same transition, it was consistent with a variation of $16 \%$ in the case of the AlSi10Mg 200C parameter set as a result of there being no overlapping contours and of the increased substrate temperature. The strength of the additively manufactured AlSi10Mg thread can be $24 \%$ higher for M5 and 49\% higher for M8 than the conventionally manufactured Al-6082 thread. No significant difference in the thread-stripping force was observed when the recoater angle was changed.

Though the $90^{\circ}$ inclination can yield favorable results, for example in the case of flatness, surface roughness, and threadstripping force, the subsequent duration and the cost of the print job would be maximum compared with the $0^{\circ}$ inclination with the plate-type parts that were tested. Thus, designers should consider the trade-offs between the desired properties and the duration and cost of the print job.

Additionally, since no significant difference was observed when the recoater angle was changed, the recoater angle should be selected in a manner that minimizes the initial contact of the part edges with the recoater and allows possible expansion of the part towards the recoating direction to increase the probability of a successful print job.

Lastly, if a pre-hole is desirable to avoid large drilling thrust forces that may hinder the structural integrity of a component, designers should consider introducing a machining allowance of $0.3 \mathrm{~mm}$ for the critical surfaces, to ensure the removal of the surface overlapping contours containing surface and/or sub-surface porosity for the AlSi10Mg_Flex parameter set.

Acknowledgements The authors extend their deepest regards to Roy Björkstrand (Aalto University) and Eero Virtanen (EOS Finland) for valuable discussions. Special thanks are extended to the staff of EOS Finland for providing the additively manufactured parts.

Funding information Open access funding provided by Aalto University. This research was funded by the FIN3D project at the Department of Mechanical Engineering, Aalto University, Finland.

\section{Compliance with ethical standards}

The work was accomplished according to the ICMJE authorship guidelines that comply with ethical standards.

Conflict of interest The authors declare that they have no conflict of interest.

Open Access This article is licensed under a Creative Commons Attribution 4.0 International License, which permits use, sharing, adaptation, distribution and reproduction in any medium or format, as long as you give appropriate credit to the original author(s) and the source, provide a link to the Creative Commons licence, and indicate if changes were made. The images or other third party material in this article are included in the article's Creative Commons licence, unless indicated otherwise in a credit line to the material. If material is not included in the article's Creative Commons licence and your intended use is not permitted by statutory regulation or exceeds the permitted use, you will need to obtain permission directly from the copyright holder. To view a copy of this licence, visit http://creativecommons.org/licenses/by/4.0/. 


\section{References}

1. Wohlers Associates Inc. (2019) Wohlers report. Wohlers Associates Inc., Colorado

2. Premiere at Mercedes-Benz Trucks: New from the 3D printer: the first spare part for trucks made of metal. In: marsMediaSite. https:// media.daimler.com/marsMediaSite/en/instance/ko/Premiere-atMercedes-Benz-Trucks-New-from-the-3D-printer-the-first-sparepart-for-trucks-made-of-metal.xhtml?oid=23666435. Accessed 6 Jan 2020

3. Totin A, Macdonald E, Conner B (2019) Additive manufacturing for aerospace maintenance and sustainment. 6:4-11

4. Akmal JS, Salmi M, Mäkitie A et al (2018) Implementation of industrial additive manufacturing: intelligent implants and drug delivery systems. J Funct Biomater. https://doi.org/10.3390/ jfb 9030041

5. Tuomi J, Paloheimo K-S, Björkstrand R et al (2010) Medical applications of rapid prototyping - from applications to classification. Innov Dev Des Manuf:701-704. https://doi.org/10.1201/ 9780203859476.ch109

6. Salmi M, Partanen J, Tuomi J et al (2018) Digital spare parts. Aalto University

7. Jalava K, Salmi M, Kukko K, Orkas J (2018) Multi-scale topologically optimized components made by casting and additive manufacturing. 73rd world foundry congress, congress proceedings, pp 141-142

8. ISO/ASTM 52900(en), Additive manufacturing - General principles — Terminology. https://www.iso.org/obp/ui/\#iso:std:iso-astm: 52900:dis:ed-2:v1:en. Accessed 23 Nov 2019

9. Takata N, Kodaira H, Sekizawa K et al (2017) Change in microstructure of selectively laser melted AlSi10Mg alloy with heat treatments. Mater Sci Eng A 704:218-228. https://doi.org/10.1016/j. msea.2017.08.029

10. Kannan GB, Rajendran DK (2017) A review on status of research in metal additive manufacturing. In: Wimpenny DI, Pandey PM, Kumar LJ (eds) Advances in 3D printing \& additive manufacturing technologies. Springer, Singapore, pp 95-100

11. Yang T, Liu T, Liao W et al (2019) The influence of process parameters on vertical surface roughness of the AlSi10Mg parts fabricated by selective laser melting. J Mater Process Technol 266:26-36. https://doi.org/10.1016/j.jmatprotec.2018.10.015

12. Kokkonen $\mathrm{P}$, Salonen L, Virta $\mathrm{J}$ et al Design guide for additive manufacturing of metal components by SLM process. VTT, Espoo

13. Gibson I, Rosen DW, Stucker B (2010) Additive manufacturing technologies: rapid prototyping to direct digital manufacturing. Springer, London

14. Zhang Y, Zhang J (2017) Finite element simulation and experimental validation of distortion and cracking failure phenomena in direct metal laser sintering fabricated component. Addit Manuf 16:49-57. https://doi.org/10.1016/j.addma.2017.05.002

15. Krol TA, Zaeh MF, Seidel C (2012) Optimization of supports in metal-based additive manufacturing by means of finite element models. Proceedings of the international solid freeform fabrication symposium, $\mathrm{p}$ 707-718

16. Gu D, Shen Y (2009) Balling phenomena in direct laser sintering of stainless steel powder: metallurgical mechanisms and control methods. Mater Des 30:2903-2910. https://doi.org/10.1016/j. matdes.2009.01.013

17. Gusarov AV, Laoui T, Froyen L, Titov VI (2003) Contact thermal conductivity of a powder bed in selective laser sintering. Int $\mathrm{J}$ Heat Mass Transf 46:1103-1109. https://doi.org/10.1016/S00179310(02)00370-8

18. Anwar AB, Pham Q-C (2017) Selective laser melting of AlSi10Mg: effects of scan direction, part placement and inert gas flow velocity on tensile strength. J Mater Process Technol 240:388-396. https:// doi.org/10.1016/j.jmatprotec.2016.10.015

19. Huang Y, Yang LJ, Du XZ, Yang YP (2016) Finite element analysis of thermal behavior of metal powder during selective laser melting. Int J Therm Sci 104:146-157. https://doi.org/10.1016/j. ijthermalsci.2016.01.007

20. Calignano F, Manfredi D, Ambrosio EP et al (2013) Influence of process parameters on surface roughness of aluminum parts produced by DMLS. Int J Adv Manuf Technol 67:2743-2751. https:// doi.org/10.1007/s00170-012-4688-9

21. Buchbinder D, Meiners W, Pirch N et al (2013) Investigation on reducing distortion by preheating during manufacture of aluminum components using selective laser melting. J Laser Appl 26:012004. https://doi.org/10.2351/1.4828755

22. Klingbeil NW, Beuth JL, Chin RK, Amon CH (2002) Residual stress-induced warping in direct metal solid freeform fabrication. Int J Mech Sci 44:57-77. https://doi.org/10.1016/S0020-7403(01) 00084-4

23. Mukherjee T, Zhang W, DebRoy T (2017) An improved prediction of residual stresses and distortion in additive manufacturing. Comput Mater Sci 126:360-372. https://doi.org/10.1016/j. commatsci.2016.10.003

24. Casati R, Hamidi Nasab M, Coduri M et al (2018) Effects of platform pre-heating and thermal-treatment strategies on properties of AlSi10Mg alloy processed by selective laser melting. Metals 8:954. https://doi.org/10.3390/met8110954

25. Aboulkhair NT, Simonelli M, Parry L et al (2019) 3D printing of aluminium alloys: additive manufacturing of aluminium alloys using selective laser melting. Prog Mater Sci 106:100578. https:// doi.org/10.1016/j.pmatsci.2019.100578

26. Aboulkhair NT, Everitt NM, Ashcroft I, Tuck C (2014) Reducing porosity in AlSi10Mg parts processed by selective laser melting. Addit Manuf 1-4:77-86. https://doi.org/10.1016/j.addma.2014.08. 001

27. Mohammadi M, Asgari $\mathrm{H}$ (2018) Achieving low surface roughness AlSi10Mg 200C parts using direct metal laser sintering. Addit Manufact 20:23-32. https://doi.org/10.1016/j.addma.2017.12.012

28. Ning Y, Wong YS, Fuh JYH, Loh HT (2006) An approach to minimize build errors in direct metal laser sintering. IEEE Trans Autom Sci Eng 3:73-80. https://doi.org/10.1109/TASE.2005. 857656

29. Tang M, Pistorius PC (2017) Oxides, porosity and fatigue performance of AlSi10Mg parts produced by selective laser melting. Int J Fatigue 94:192-201. https://doi.org/10.1016/j.ijfatigue.2016.06. 002

30. EOS additive manufacturing of high-quality metal parts. https:// www.eos.info/systems solutions/metal. Accessed 7 Jun 2019

31. Asgari H, Baxter C, Hosseinkhani K, Mohammadi M (2017) On microstructure and mechanical properties of additively manufactured AlSi10Mg 200C using recycled powder. Mater Sci Eng A 707:148-158. https://doi.org/10.1016/j.msea.2017.09.041

32. Rao PN (2013) Manufacturing technology. Tata McGraw-Hill Education

33. ISO 8062-3:2007(en), Geometrical product specifications (GPS) dimensional and geometrical tolerances for moulded parts - Part 3: General dimensional and geometrical tolerances and machining allowances for castings. https://www.iso.org/obp/ui/\#iso:std:iso: 8062:-3:ed-1:v1:en. Accessed 3 Jan 2020

34. Hanumaiah N, Ravi B (2007) Rapid tooling form accuracy estimation using region elimination adaptive search-based sampling technique. Rapid Prototyp J 13:182-190. https://doi.org/10.1108/ 13552540710750933

35. Paul R, Anand S, Gerner F (2014) Effect of thermal deformation on part errors in metal powder based additive manufacturing processes. J Manuf Sci Eng 136:031009. https://doi.org/10.1115/1.4026524 
36. Olakanmi EO, Cochrane RF, Dalgarno KW (2015) A review on selective laser sintering/melting (SLS/SLM) of aluminium alloy powders: processing, microstructure, and properties. Prog Mater Sci 74:401-477. https://doi.org/10.1016/j.pmatsci.2015.03.002

37. Maamoun AH, Elbestawi M, Dosbaeva GK, Veldhuis SC (2018) Thermal post-processing of AlSi10Mg parts produced by selective laser melting using recycled powder. Addit Manuf 21:234-247. https://doi.org/10.1016/j.addma.2018.03.014

38. Totten GE, Funatani K, Xie L (2004) Handbook of metallurgical process design, 1st edn. CRC Press, New York

39. Kempen K, Thijs L, Van Humbeeck J, Kruth J-P (2012) Mechanical properties of AlSi10Mg produced by selective laser melting. Phys Procedia 39:439-446. https://doi.org/10.1016/j.phpro.2012.10.059

40. Galy C, Le Guen E, Lacoste E, Arvieu C (2018) Main defects observed in aluminum alloy parts produced by SLM: from causes to consequences. Addit Manuf 22:165-175. https://doi.org/10. 1016/j.addma.2018.05.005

41. Papadakis L, Loizou A, Risse J, Schrage J (2014) Numerical computation of component shape distortion manufactured by selective laser melting. Procedia CIRP 18:90-95. https://doi.org/10.1016/j. procir.2014.06.113

42. Kruth J-P, Levy G, Klocke F, Childs THC (2007) Consolidation phenomena in laser and powder-bed based layered manufacturing. CIRP Ann 56:730-759. https://doi.org/10.1016/j.cirp.2007.10.004

43. Kimura T, Nakamoto T (2016) Microstructures and mechanical properties of $\mathrm{A} 356$ (AlSi7Mg0.3) aluminum alloy fabricated by selective laser melting. Mater Des 89:1294-1301. https://doi.org/ 10.1016/j.matdes.2015.10.065

44. Force Sensors. https://www.kistler.com/en/products/components/ force-sensors/. Accessed 10 Jun 2019
45. Walter Tools » Engineering Kompetenz. https://www.walter-tools. com/en-gb/pages/default.aspx. Accessed 9 Jun 2019

46. ISO 2768-1:1989(en), General tolerances - Part 1: Tolerances for linear and angular dimensions without individual tolerance indications. https://www.iso.org/obp/ui/\#iso:std:iso:2768:-1:ed-1:v1:en. Accessed 4 Jan 2020

47. Hague R, Mansour S, Saleh N (2004) Material and design considerations for rapid manufacturing. Int J Prod Res 42:4691-4708. https://doi.org/10.1080/00207840410001733940

48. Sames WJ, Medina F, Peter WH et al (2014) Effect of process control and powder quality on Inconel 718 produced using Electron beam melting. In: 8th international symposium on Superalloy 718 and derivatives. John Wiley \& Sons, Ltd, pp 409 423

49. DeVries WR (1992) Analysis of material removal processes. Springer-Verlag, New York

50. Oliaei SNB, Karpat Y (2016) Investigating the influence of built-up edge on forces and surface roughness in micro scale orthogonal machining of titanium alloy Ti6Al4V. J Mater Process Technol 235:28-40. https://doi.org/10.1016/j.jmatprotec.2016.04.010

51. Gökkaya H (2010) The effects of machining parameters on cutting forces, surface roughness, built-up edge (BUE) and built-up layer (BUL) during machining AA2014 (T4) alloy. Strojniski Vestnik/ journal of mechanical engineering 56

52. Rosenthal I, Stern A, Frage N (2017) Strain rate sensitivity and fracture mechanism of AlSi10Mg parts produced by selective laser melting. Mater Sci Eng A. https://doi.org/10.1016/j.msea.2016.11.070

Publisher's note Springer Nature remains neutral with regard to jurisdictional claims in published maps and institutional affiliations. 